The Internal Magnetization of Seamounts and Its

\title{
Computer Calculation
}

GEOLOGICAL SURVEY PROFESSIONAL PAPER 554-F

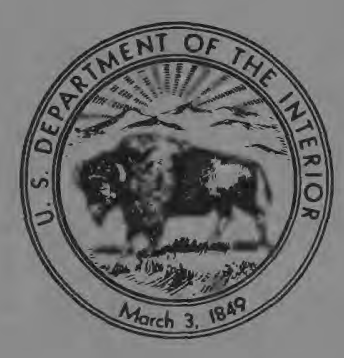




\section{The Internal Magnetization of Seamounts and Its \\ Computer Calculation}

By BERNARDO F. GROSSLING

SHORTER CONTRIBUTIONS TO GENERAL GEOLOGY.

GEOLOGICAL SURVEY PROFESSIONAL PAPER 554-F

The triple-field method of calculating the internal magnetization of a seamount, or other geologic body, from its shape and its magnetic anomaly

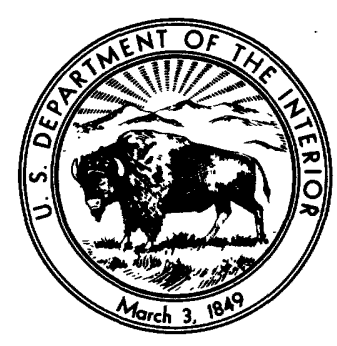

UNITED STATES GOVERNMENT PRINTING OFFICE, WASHINGTON:1967 


\section{UNITED STATES DEPARTMENT OF THE INTERIOR \\ STEWART L. UDALL, Secretary \\ GEOLOGIGAL SURVEY \\ William T. Pecora, Director}

For sale by the Superintendent of Documents, U.S. Government Printing Office

Washington, D.C. 20402 - Price 75 cents (paper cover) 


\section{CONTENTS}

Symbols.

Abstract ... . . . . . . .

Introduction and acknowledgments . . . . . . . . . .

Seamounts and their magnetization.

The nature of seamounts. . .

The magnetization of seamounts...............

Thermoremanent magnetization of lavas.......

The magnetization of a submarine volcano.....

Virtual paleomagnetic poles..................

Importance of the magnetization of seamounts .

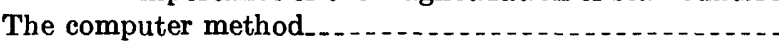

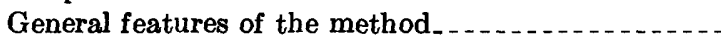

Scheme of mass approximation . . . . .

The field of the elementary prism...............

Determination of the magnetic field with the Gravity

Slave.

\begin{tabular}{|c|c|}
\hline Page & \\
\hline Fiv & The computer method-Continued \\
\hline 1 & Biased-field anomaly \\
\hline 1 & Magnetic field expressed in $x, y$, and $z$ polarizations. \\
\hline 2 & The triple-field method of determining $J$ \\
\hline 2 & Total and remanent magnetizations \\
\hline 3 & Input and output of the program \\
\hline 3 & The magnetizations of Maher, Boutelle, and Hoke Sea- \\
\hline 4 & (1 \\
\hline 5 & The setting of Maher, Boutelle, and Hoke Seamounts. \\
\hline 5 & The computer calculation of the magnetization of \\
\hline 6 & Maher, Boutelle, and Hoke Seamounts $\ldots$ \\
\hline 6 & Discussion of results \\
\hline 6 & $\begin{array}{l}\text { Proposed procedure to interpret the data of many sea- } \\
\text { mounts. }\end{array}$ \\
\hline 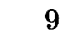 & Conclusions. \\
\hline 9 & References. \\
\hline
\end{tabular}

\section{ILLUSTRATIONS}

[Plates are in pocket]

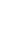
5 


\section{SYMBOLS}

$x$ coordinate of field point $P$.

$y$ coordinate of field point $P$.

$x$ coordinate of center of gravity $Q$ of a prism.

$y$ coprdinate of center of gravity $Q$ of a prism.

$z$ coordinate of center of gravity $Q$ of a prism.

Field point.

Center of gravity of a prism.

Distance $Q P$.

$U$ Gravimetric potential.

$W \quad$ Magnetic potential.

$\gamma$ Universal gravitational constant.

$K \quad$ Magnetic susceptibility.

$\Omega \quad$ Intensity of biasing field.

Angle of inclination of the biasing field, positive below the horizontal plane.

Angle of declination of the biasing field, positive east of north.

Total magnetization vector (shown in lightface italic with an arrow above on illustrations).

Angle of inclination of the total magnetization, positive below the horizontal.

Angle of declination of the total magnetization, positive east of north.

$J_{n} \quad$ Remanent magnetization vector.

$i_{n} \quad$ Angle of inclination of the remanent magnetization, positive below the horizontal.

$\delta_{n} \quad$ Angle of declination of the remanent magnetization, positive east of north.

$Q_{n} \quad$ Ratio $J_{n} /(K \Omega)$.

$\Delta \boldsymbol{s} \quad$ Elementary virtual displacement vector.

$u_{1} \quad x$ cosine director of $\Delta s$.

$u_{2} \quad y$ cosine director of $\Delta s$.

$u_{3} \quad z$ cosine director of $\Delta s$.

$f \quad$ Field intensity of the anomaly field.

$X \quad x$ component of $f$, similarly for $Y$ and $Z$.

$X_{(s)} \quad x$ component of $f$ when the total internal magnetization is parallel to $s$, similarly for $Y_{(s)}$ and $Z_{(s)}$.

$\Lambda \quad$ Biased-field anomaly.

$S \quad$ Grid spacing between stations.

$E \quad x$ dimension of a prism.

$F \quad y$ dimension of a prism.

$A \quad x$ coordinate of the center of symmetry of a prism array.

$B \quad y$ coordinate of the center of symmetry of a prism array.

$G \quad$ Center of top of prism array.

$H_{0} \quad z$ coordinate of the top of a prism array.

$H_{k} \quad$ Thickness of $k$ layer; $k=1, \ldots, 10$.

$d_{k} \quad$ Density of $k$ layer; $k=1, \ldots, 10$.

$d^{\prime}{ }_{k} \quad$ Virtual density of $k$ layer in magnetic problems; $k=1, \ldots, 10$.

$k \quad$ Layer number; $k=1, \ldots, 10 ; k=1$ for top layer.

$n \quad$ Row number; $n=1, \ldots, 20$. In a given layer, row 1 is the first row in the positive $y$ direction.

The symbol $n$ is used also as sequential index as specifically indicated in text.

$l \quad$ Prism number; $l=1, \ldots, 20$. In a given row, prism 1 is the first prism in the positive $x$ direction.

$V_{1} \quad$ First prism number of the first segment in a given row.

$W_{1} \quad$ Last prism number of the first segment in a given row.

$V_{2} \quad$ First prism number of the second segment in a given row.

$W_{2} \quad$ Last prism number of the second segment in a given row.

$i \quad$ Subscript, denotes number of a column in the grid of stations. Column 1 is that with algebraically smallest $x$ of the grid. The symbol $i$ is also used to denote inclination of the total magnetization.

Subscript, denotes number of a row in the grid of stations. Row 1 is that with algebraically smallest $y$ of the grid.

$n \quad$ Order number of filled prisms.

$N \quad$ Number of filled prisms.

$v \quad$ Order number of stations in grid.

$\Upsilon \quad$ Number of stations in grid.

$\sigma \quad$ Order number of a region.

$T$ Temperature.

Time.

Latitude.

Longitude.

Sum of squares of errors, in adjusting calculated to observed fields.

IV 
SHORTER CONTRIBUTIONS TO GENERAL GEOLOGY

\title{
THE INTERNAL MAGNETIZATION OF SEAMOUNTS AND ITS GOMPUTER GALGULATION
}

\author{
By Bernardo F. Grossling
}

\begin{abstract}
Seamounts are veritable markers of the paleomagnetic field. Their magnetizations can be determined by an analysis of the magnetic anomaly in relation to the seamount shape. Probably most seamounts are thermoremanently magnetized. The method presented, which is not limited to seamounts, gives the total magnetization vector from a comparison of the observed field with three hypothetical fields obtained by assuming unit magnetizations in three orthogonal directions. A least-squares fit of a linear combination of the three fields to the observed one gives the magnetization components. By examining the relationship between $J$ and $J_{n}$ as a function of $K$, limits can be established for $J_{n}$; a locus for the virtual pole can be calculated as a function of $K$. For the computer model, ensembles of rectangular prisms are used. Four of the harmonic functions of the potential are taken into account. The derivatives of the magnetic potential are computed by a numerical differentiation of the corresponding gravimetric derivatives. The concept of "biasedfield anomaly" as an algorithm built in the program gives the option of obtaining either (a) an arbitrary component of the anomaly field intensity, (b) the conventional total-intensity anomaly, or (c) the magnitude of the anomaly field intensity. As an illustration, the magnetizations of Maher, Boutelle, and Hoke Seamounts, located in the northeastern Pacific, are determined. In Maher, the magnetization is predominantly east; in Boutelle, $126^{\circ} \mathrm{W}$; and in Hoke, $17^{\circ} \mathrm{E}$. With the deviations found, any rotation of crustal blocks in Maher and Boutelle Seamounts, due to crustal shearing along the Murray and Mendocino fracture zones, respectively, would be consistent as to direction of rotation. Alternative explanations of the deviations are also examined. A systematic analysis of the magnetization of seamounts in the northeast Pacific may be useful in deciphering crustal displacements and rotations.
\end{abstract}

\section{INTRODUCTION AND ACKNOWLEDGMENTS}

This paper discusses the magnetization of seamounts and describes its determination, using computer methods that I developed in 1959-1960 while with the Chevron Research Co. (formerly the California Research Corp.). The actual analysis of the problem of the seamounts and the paper itself were prepared later, after I joined the U.S. Geological Survey. I wish to thank the Chevron Research Co. for its permission to publish this work and for its kind cooperation in the preparation of many of the illustrations. The bathym- etry and the total-intensity magnetic anomalies on Maher, Boutelle, and Hoke Seamounts were furnished to me by the Scripps Institution of Oceanography and are small detailed parts of the surveys by Mason and Raff (1961) and Vacquier, Raff, and Warren (1961). The bathymetry was collected in the course of several expeditions wholly supported under contract with the Office of Naval Research. The criticisms received from J. R. Balsley, R. G. Henderson, M. K. Hubbert, H. W. Menard, and F. J. Vine are sincerely appreciated. Finally, I am grateful to Professor Victor Vacquier for suggesting the problem of the seamounts.

The work originated from a computer program for the calculation of the gravity field produced by a body of arbitrary shape. In this program, nicknamed the Gravity Slave, the body is approximated by sets of rectangular prisms. Taking advantage of the inherently high precision of a digital computer, I extended the method to the calculation by numerical approximation of the derivatives of the field components. In particular, this permitted the calculation of the magnetic field produced by a body uniformly magnetized. A variant of the Gravity Slave program aimed especially at aeromagnetic interpretation was then prepared. This program can calculate the anomaly field under different assumptions about the direction of the internal magnetization. Taking advantage of this feature, I then developed a method-named the triple-field method - to determine the direction and magnitude of the internal magnetization when, in addition to the shape of the body, the anomaly field is known and a uniform internal magnetization is assumed.

In geology two different techniques have been used to determine the remanent magnetization. The one most widely used involves an actual measurement on a sample of the rock. The other-which in a certain way is an outgrowth of the interpretation of magnetic anomalies in prospecting-is based on the analysis of the magnetic anomaly produced by the geologic body examined. It consists of the calculation of the magnetic anomaly for a model of the geologic body, under 
different assumptions about the internal magnetization, with the intent of reproducing the anomaly observed. The first technique cannot as yet be applied to seamounts because of the difficulty of obtaining oriented core samples in deep ocean waters. On the other hand, the second is facilitated by the existence, for certain areas of the oceans, of air- or ship-borne magnetic surveys and of detailed bathymetric maps.

The results from the two techniques are not directly comparable. The measurement on a sample gives the remanent magnetization, whereas the anomaly analysis gives the total magnetization; that is, the remanent plus the induced magnetization. Further, the anomaly analysis provides a kind of average of the direction of the geomagnetic field throughout a geologic body.

The direction and intensity of the remanent magnetization usually vary throughout geologic bodies. Slumping, flow, tectonic deformation, and other factors may cause such variation. To obtain an accurate value of the average direction for a complex body, such as a seamount, would require a large number of samples taken not only near the surface but also in the interior of the body. The practice of renoving unstable components of the remanent magnetization in the laboratory is another source of discrepancy between the two techniques, for the analysis of a magnetic anomaly refers to the condition as it occurs in nature.

The average obtained by anomaly analysis would be most meaningful when the main component of the geomagnetic field has varied only slightly in direction during the period of acquisition of the magnetization. If the remanent magnetization changes, especially in direction, in an erratic or too complex a manner throughout the geologic body, the average may not be significant. If the geomagnetic field has been reversed numerous times during the period of acquisition of the remanent magnetization and if the body consists of several layers or regions-such as a volcano-which are magnetized in alternate directions, then the anomaly field would be weak and indistinct; for the fields of successive layers or regions would practically cancel each other, and the anomaly analysis would fail to provide a meaningful average magnetization. But if the anomaly is distinct and can be reproduced accurately by the modeling, then it can be inferred that the magnetization used in or derived from the calculation is probably meaningful.

Several papers have been published on the computer calculation of the magnetic anomaly produced by a given body when the direction of magnetization is also given. Thereby the direction may be determined by a trial-and-error procedure. We will mention only some of the more recent ones. Bott (1963) calculated the magnetic anomaly by two alternative methods, one using a surface integration and the other a volume integration. Morgan and Grant (1963) calculated the gravity and the magnetic anomaly for two-dimensional bodies by approximating the cross section by a polygon. Talwani and Heirtzler (1964) used the closed expression for the magnetic anomaly caused by a two-dimensional polygon. Bhattacharyya (1964) used a closed mathematical expression for the total-intensity anomaly corresponding to a rectangular prism of infinite vertical sides.

Several papers have been published on the investigation of oceanic features with the magnetic method. Press and Ewing (1952) computed theoretical magnetic anomalies for typical two-dimensional oceanic structures. Laughton, Hill, and Allan (1960), using a oneprism model and assuming magnetization parallel to the present geomagnetic field, analyzed the magnetic anomaly of a seamount north of Madeira. Also, Gerald Van Voorhis (in U.S. Naval Oceanographic Office, 1962) and Van Voorhis and Walczak (1963) investigated the magnetization of seamounts with the computer program utilized by Vacquier (1962b).

In the triple-field method of analysis of an anomaly, the magnetization is directly calculated, that is, without trial-and-error. Vacquier (1962b) and Henderson and Allingham (1964) used it to determine the magnetization of two buttes in Montana. Their model is a set of rectangular prisms. The magnetization of each prism is approximated by magnetic particles located at the center of opposing faces of the prism. By comparison, in the method to be described in this paper, the first four terms of the potential expansion are used, which allow the use of relatively larger prisms for the same relative error. Another difference is that the magnetic components will be calculated by a numerical differentiation of "virtual" gravimetric components.

This paper begins with an analysis of how a seamount may become magnetized. Then the Gravity Slave program is briefly described, and the theory of the triple-field method is presented in extent. As an illustration, the magnetizations of three seamounts off California are determined. Finally, the discrepancies between the direction of the internal magnetization in these seamounts and the geomagnetic field are discussed in relation to the geology of the northeast Pacific, where the three seamounts are located.

\section{SEAMOUNTS AND THEIR MAGNETIZATION THE NATURE OF SEAMOUNTS}

The oceans are dotted with submarine mountains. Inside the andesite line, the bedrock in all of them is basalt. In the Pacific Ocean the total number of these submarine mountains is estimated at about 10,000 (Menard, 1959). About 2,000 have already been found, 
of which about 1,000 are in the Baja California seamount province, delimited by the Murray and Clarion fracture zones (Menard and Ladd, 1963). Some of them, designated as seamounts, have conical shapes, and are either active volcanoes or believed to be extinct ones. Some seamounts have flat tops, which Hess (1946) interpreted as wave erosion at a time when they stood with their tops near the ocean's surface. Since then, these flat-topped seamounts, or guyots as designated by Hess (1946), would have subsided. Nayudu (1962) suggests that some of the flat tops may be primary features. If this were true - that is, that some guyots were not subsided seamounts-then the oceanic crust would have a long-term strength at least sufficient to support them.

Because the evidence about their age is scant, the limits for their time of formation are too broad. The intense weathering of oceanic basalts has precluded radioactive age determinations. Heezen and Menard (1963) indicated that Cretaceous fossils are the oldest sampled from seamounts. Menard and Ladd (1963) believed that either all seamounts are post-Paleozoic or that in Paleozoic time the seamount volcanism was relatively weak. This volcanic activity would have culminated in late Paleozoic to early Cenozoic times. Erben Guyot (lat $32^{\circ} 50^{\prime}$ N., long $132^{\circ} 32^{\prime}$ W.), which became submerged by Miocene time (Carsola and Dietz, 1952), is about 300 nautical miles northwest of Hoke Seamount, one of the seamounts studied in this paper. Hamilton (1956) discussed guyots some 6001,100 miles west of Hawaii and indicated that they formed a chain of islands in Cretaceous time.

\section{THE MAGNETIZATION OF SEAMOUNTS}

\section{THERMOREMANENT MAGNETIZATION OF LAVAS}

Because of certain properties of their constituent lavas, seamounts are actual markers of the geomagnetic field which existed at the time of their formation. The magnetization of a lava is seated in the iron oxides and sulfides which exhibit ferromagnetism. Their magnetization disappears at the Curie point temperature. Above the Curie point the mineral becomes paramagnetic. The most important Curie point is that corresponding to magnetite, namely $578^{\circ} \mathrm{C}$. Some lavas exhibit a second Curie point at about $250^{\circ} \mathrm{C}$. A lava placed in a steady magnetic field $\vec{\Omega}$ acquires, during its cooling below the Curie temperature, a remanent magnetization $\boldsymbol{J}_{n}$ which is designated as thermoremanent magnetization (TRM). This has been shown both by laboratory experiments and by measurements on field samples (Nagata, 1953). For example, recently cooled lavas acquire magnetizations which are accurately parallel to the direction of the present geomagnetic field. Measurements on recent igneous rocks, including lavas, show that their remanent magnetizations are parallel to the direction of the axial geocentric dipole, thus the secular variation is averaged out. The TRM is of great stability.

The TRM is progressively acquired as the temperature falls below the Curie point or points. Nagata (1953, p. 142) defined the TRM as "the remanent magnetization after field cooling throughout in a weak magnetic field from $T$ to $0^{\circ} \mathrm{C}$." Below about $100^{\circ} \mathrm{C}$, however, the magnetization is increased only by negligible amounts. Furthermore, most of the magnetization is acquired when the temperature is in the interval from the Curie point to the Curie point minus about $100^{\circ} \mathrm{C}$ (Nagata, 1953, p. 146).

Nagata (1953) defined a function

$$
P(T)=\frac{1}{H} \frac{\partial J}{\partial T}
$$

designated as "characteristic function of TRM," which is the rate of production of remanent magnetization per degree centigrade per unit field applied. Here $H$ denotes the field intensity, $J$ the thermoremanent magnetization, and $T$ the temperature.

In this treatment, $T$ is taken as the temperature increasing with time, for Nagata is assuming reversibility with temperature of the magnetization process. In the cooling process, however, $T$ decreases with time. We assume that not only $T$ is a function of time $(t)$, but that $H$ is also. If we replace $T$ by $T^{\prime}=T_{c}-T$, that is, if we measure the temperature from the highest Curie point downwards, then we have the same sense of the $t$ scales for the $T^{\prime}$ and $H$ variables. Because of this, we can rewrite equation 1 in the form

$$
P\left(T^{\prime}\right)=\frac{1}{H} \frac{\partial J}{\partial T^{\prime}}
$$

Nagata found experimentally that the remanent magnetizations acquired in definite temperature intervals are additive; hence when $H$ is constant throughout the cooling,

$$
J=H \int_{0}^{T^{\prime \prime}} P\left(T^{\prime}\right) d T^{\prime} .
$$

He does not indicate whether this additive law would be valid for changes in the direction of $\boldsymbol{H}$, which may occur during the cooling of the seamount. That is, we don't know whether the following generalization of equation 3

$$
\boldsymbol{J}=\int_{0}^{T^{\prime}} \boldsymbol{H} P\left(T^{\prime}\right) d T^{\prime}
$$

is valid or not. 
If $\boldsymbol{H}$ varies only in magnitude during the cooling, then

$$
J=-\int_{t_{1}}^{t_{2}} H(t) P\left\{T_{c}-T(t)\right\} \frac{d T}{d t} d t .
$$

Because $\frac{d T}{d t}$ is negative and $P(T)$ is positive, the direction of $\boldsymbol{J}$ is the same as that of $\boldsymbol{H}$. Therefore, the TRM acquired by a rock is not simply determined by the time-average value of $H$ during the period of acquisition of the TRM, but $H$ is weighted by the characteristic function $P(T)$.

Many factors-apparently depending on obscure petrologic details-determine the function $P(T)$. Hence, without having a sample of the rock, it would be difficult, if not impossible, to deduce which intensity the paleomagnetic field had when the TRM was acquired.

\section{THE MAGNETIZATION OF A SUBMARINE VOLCANO}

Because of its complexity, we can only visualize the major stages in the magnetization of a submarine volcano; that is, of a seamount. The following discussion is intended as a sketch of the phenomena involved.

Present-day magmas reach the earth's surface with temperatures of about $900^{\circ}-1200^{\circ} \mathrm{C}$, depending on their composition. Hawaiian tholeiitic basalt magmas reach the surface with temperatures of $1050^{\circ}-1200^{\circ} \mathrm{C}$ (MacDonald, 1963). At these temperatures a basaltic magma behaves like a viscous fluid, its viscosity being about $10^{2}-10^{5}$ times that of water (Wentworth and others, 1945). As the temperature decreases the viscosity increases, and fluidlike motion ceases at about $800^{\circ} \mathrm{C}$. Hawaiian basaltic lava shows a small amount of movement at about $760^{\circ} \mathrm{C}$ (MacDonald and Finch, 1950). By the time the highest Curie point, namely $578^{\circ} \mathrm{C}$, is reached, a basaltic lava is already a solid.

In the early stages of a submarine volcano, the structure and temperature distribution are probably of great complexity. The outer layers of magma oozing at the surface of the incipient volcano would be quickly chilled and thus form a resistant stretchable skin. Flow may continue inside, with the formation of pillow lavas (Rittmann, 1962, p. 70-74). Eventually these outer layers are fractured and are repeatedly incorporated into the fluid by continued flow. The overall magnetic field of the volcano would be weakened by the disordered mingling of shell fragments and by the demagnetization caused by reheating of the fragments. The magma injected into and retained in the shallow volcanic chamber would bulge and distend the upper crust, and produce tear breaks followed by water invasion and magma outflow. The relative importance of these two kinds of mechanisms of growth, namely chamber injection and outpouring of magma, is not known; however, the first might be the more important in submarine volcanoes because of the formation of a strong outer shell when magma is chilled by water.

As the major eruptive phase comes to an end, the local irregularities in the temperature distribution would begin to disappear and the local pockets of magma would solidify. The neck, or dike-type feeder, would have solidified or have been severed and thus ceased the transport of hot magma from below. Thereafter, the flow of heat in the volcanic mass would be essentially controlled by the outer boundary conditions. At this stage in the history of the volcano, the points with temperature equal to the $578^{\circ} \mathrm{C}$ Curie point would form a bulblike surface, inside of which the material is paramagnetic and thus has a weaker magnetization than the outer thermoremanently magnetized zone. This zone would increase in thickness with further cooling. The material still fluid would form a chamber surrounded by the shell of paramagnetic solidified rocks enclosed by the Curie surface. As the cooling proceeds this chamber would contract and finally disappear. With still further cooling, the Curie surface would continue to contract, until it would be reduced to a point and then disappear.

An important consequence of the process described is the remagnetization of the crustal rocks underlying the volcanic mass. Any earlier thermoremanent magnetization of these rocks would be lost to the extent that they are reheated. On reaching the Curie point the earlier TRM would be completely lost, and then TRM would be reacquired when the temperature falls again below the Curie point. Hence in making a computer model of a seamount, allowance should be made for such a root; however, we have not yet taken this effect into consideration in our calculations.

The time required to dissipate the heat of a submarine volcano is but a brief episode in comparison to geologic time, which encompasses billions of years. A simple model can serve to set an upper estimate for the order of magnitude of the cooling time. Let us consider a homogeneous infinite medium in which, at $t=0$, the temperature is $T=T_{0}$ in a spherical zone of radius $R$ of the medium, and $T=0$ outside the zone. Such a model will overestimate the time required for the cooling of a pocket of lava or of a magnia chamber. First, the presence of the earth's free surface shortens the cooling time with respect to an infinite medium. Second, heat is transported while the lava is fluid not only by conduction but also by convection, which is a more vigorous mechanism. In the model just described the center of the spherical zone remains as the highest 
temperature point through the entire cooling process. The temperature $T_{a}$ at the center, at time $t$, is given by the following equation (Ingersoll and others, 1954, p. 141):

$$
T_{a}=T_{0}[\phi\{x /(2 \sqrt{\alpha t})\}-2 x Z(x)],
$$

where $x=R /(2 \sqrt{\alpha t}), \alpha$ is the thermal diffusivity, $\phi$ is the probability integral, and $Z(x)$ is the normal probability density function. In equation 6 the nomenclature of Ingersoll, Zobel, and Ingersoll (1954) is retained, although some of the letters are used elsewhere in this paper for other purposes.

As for the thermoremanent magnetization, it is not necessary to consider cooling below about $100^{\circ} \mathrm{C}$, that is, $T_{a}=0.1 T_{0}$ because $T_{0}=1050^{\circ}-1200^{\circ} \mathrm{C}$. The equation gives $T_{a}=0.1 T_{0}$ for $x=0.765$. If we assume $\alpha=$ 0.010 in cgs (centimeter-gram-second) units, then $t=$ 790,000 years for $R=1$ kilometer, $t=7,900$ years for $R=100$ meters, and $t=79$ years for $R=10$ meters. This demonstrates that the heat of small pockets of lava would be dissipated, at most, within a few decades and that, even for a magma chamber, not more than about $1 \mathrm{~m} . \mathrm{y}$. (million years) have to be considered.

Because the ages of the three seamounts which we have been studying are probably of the order of tens or even hundreds of millions of years, their complete masses should be well below the $578^{\circ} \mathrm{C}$ Curie point and thus can be thermoremanently magnetized throughout. This would be true even if the volcanic activity of the seamounts had extended for a long period of geologic time, as long as activity had ceased tens of millions of years ago or more. On the other hand, the time of cooling - when the thermoremanent magnetization is acquired-is long in comparison with the secular variation. Thus this variation may be averaged out. Moreover, the fact that the magnetic anomalies of some seamounts may be accounted for by assuming uniform magnetization throughout indicates that the main dipole field has been relatively stable during those intervals of time when the seamounts were cooling between the Curie point and about $100^{\circ} \mathrm{C}$.

\section{Virtual paleomagnetic poles}

To utilize the direction of remanent magnetization of a seamount, it is necessary to relate this direction to the morphology of the geomagnetic field at the time when the seamount became thermomagnetized. At present, the nondipole part of the field is changing rapidly. It is conceivable that at some time in the past the contribution of the nondipole part of the field may have been larger than that of the dipole part. As a first step, however, it is customary to calculate the positions of a north or a south magnetic pole under the assumption that the field was dipolar, an assumption 243-571 $0-67-2$ neglecting the nondipole part. In the specific case of the seamounts, the features of the geomagnetic field with a life span shorter than about $0.1 \mathrm{~m}$.y. would be averaged out and not be reflected in the overall magnetization of the seamount.

Under this assumption and with the aid of spherical trigonometry (fig. 1), we can obtain the position of the virtual poles. The latitude $\phi^{\prime}$ of the virtual pole is given by

$$
\sin \phi^{\prime}=\sin \phi \cos p+\cos \phi \sin p \cos \delta_{n},
$$

and its longitude $\lambda^{\prime}$ by

$$
\sin \left(\lambda-\lambda^{\prime}\right)=\sin p \sin \delta_{n} / \cos \phi^{\prime},
$$

where $\phi$ and $\lambda$ are the latitude and longitude, respectively, of the seamount; $\delta_{n}$ is the declination of the remanent magnetization; and $p$ is the angular distance between the seamount and the virtual pole and, for a dipole field, is given by

$$
\tan i_{n}=2 \cot p,
$$

where $i_{n}$ is the inclination of the remanent magnetization (Chapman and Bartels, 1940, p. 22, formula 35).

\section{IMPORTANCE OF THE MAGNETIZATION OF SEAMOUNTE}

A knowledge of the magnetization of seamounts can be valuable in the study of the relative movements of segments of the earth's crust and of the crust as a whole with respect to the earth's magnetic field. The facts that seamounts are very numerous and that they are scattered throughout most of the oceans indicate the potential wealth of information which may be available.

As seamounts are frequently distinctive features

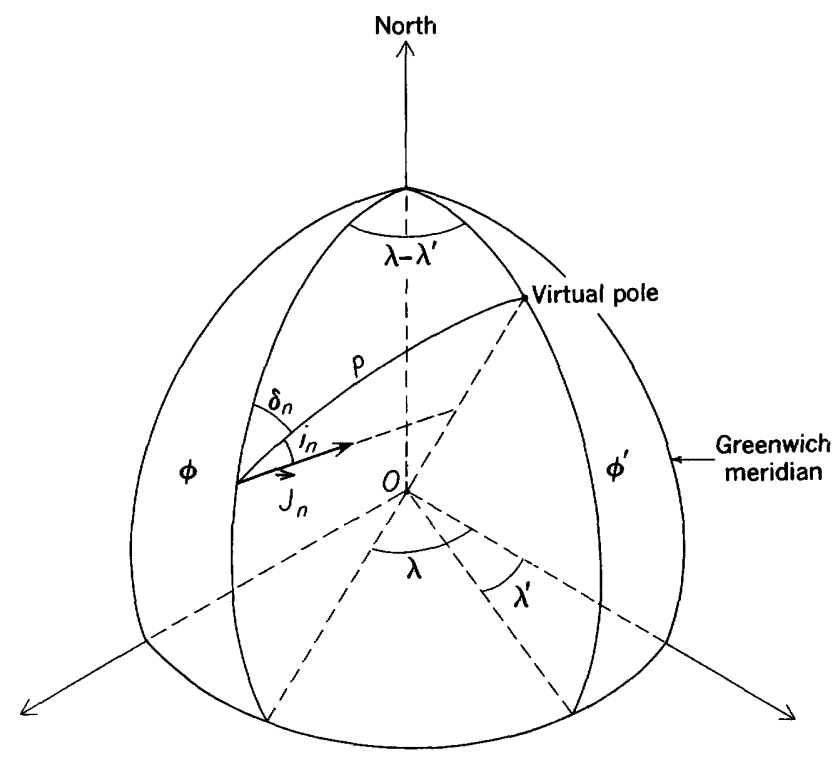

Figure 1.-Method of locating virtual pole. 
rising above the ocean floor, their associated magnetic anomalies can be analyzed in relation to their topography. This permits the determination of their total magnetization - that is, of the vector sum of the induced and of the remanent magnetizations-in the manner described in this paper.

Changes since the time of cooling, in the position of a seamount with respect to the geomagnetic field, create discrepancies between the direction of the total and induced magnetizations. Seamounts might have formed at different geologic times. In the meantime, crustal movements- such as overall shifts of the earth's crust with respect to the geomagnetic field, continental drift, and smaller scale tectonic displacements-may have taken place.

An area of particular interest for an investigation of crustal movements using the magnetization of seamounts is the Pacific Ocean west of North America. The three seamounts investigated in this paper are in this area. Vacquier, Raff, and Warren (1961) have found strong indications of very large displacements along certain linear fractures of the oceanic crust. To reconcile such large displacements in the oceanic crust with the absence of, or with only small, displacements in the neighboring continental block may require either the postulating of other types of displacements, such as rotation of crustal blocks, or an entirely new conception about the origin and evolution of the oceanic and continental crusts.

\section{THE COMPUTER METHOD}

\section{GENERAL FEATURES OF THE METHOD}

For the determination of the internal magnetization of the three seamounts, a computer program that I developed for gravity and magnetic calculations was used. Only the main characteristics of this program will be presented here.

The Gravity Slave program determines the gravimetric or magnetic field produced by bodies of arbitrary shape. The particular variant of that program used has optional channels for the calculation of the vertical component of the field intensity, a quantity designated as "biased-field anomaly," and the second vertical derivative of the biased-field anomaly. The biasedfield anomaly can be readily specialized into either (a) the conventional total-intensity anomaly (Vacquier and others, 1951), (b) the component of the anomaly field on an arbitrary direction, or (c) the magnitude of the anomaly field.

The field values are calculated at the intersections of a square grid of stations lying on a horizontal plane (fig. 2). This plane may represent the earth's surface.

The density, for the gravimetric field, and both the magnetic susceptibility and the remanent-magnetization intensity, for the magnetic field, can change stepwise with depth. The internal magnetization can have arbitrary direction and intensity.

The blocks of results are compactly stored in the computer. Despite that, various lengths of results can be handled. Thus in core storage the storage used expands and contracts like an accordion. As presently coded, the program can be run on an IBM-704, -7090 , or -7094 computer. The program was designed to relieve the user of as much routine as possible. For example, it handles the conversion of units, and the results are plotted automatically.

\section{SCHEME OF MASS APPROXIMATION}

To approximate the body in the Gravity Slave, sets of rectangular prisms are used. To facilitate the coding of such sets of prisms, they are organized in rectangular prism arrays of 4,000 elementary prisms, which contain 10 layers each with $20 \times 20$ prisms. As many prism arrays as necessary, each of different dimensions and positions, may be used. If the approximation for a given number of prisms is to be most effective, differentsized prisms locatable at arbitrary positions should be handled. The dimensions $E$ and $F$ of the prisns, the thicknesses $H_{k}$, and densities $d_{k}$ of each layer can be chosen at will. The position of the prism array is specified by means of the coordinates $A, B$, and $H_{0}$ of the center $G$ of the top of the prism array (fig. 2).

The given mass distribution is approximated by specifying which prisms of the arrays are filled with matter. A particular prism is allowed to be either filled or empty. If there are no filled prisms in a layer, its density is made equal to zero. Then, for the layers containing some filled prisms, the "rows" containing filled prisms are identified. A "row" is defined as a set of 20 prisms lying side by side in the $x$ direction (fig. 3). Each layer contains 20 rows. In a row, only one or two contiguous sequences of prisms may be occupied. No loss of generality results from this restriction because as many prism arrays as required may be used. This system allows the representation of bodies with cavities and reentrants. We may think of each row as a skewer with meat pieces, such as shish kebab. Up to two sections of adjacent pieces of "meat" are allowed per "skewer," with no more than 20 pieces per "skewer."

For the study of the problem and its computer handling, an $x y z$ system of coordinates is used, in which the $x$ axis is horizontal and points eastward. The $y$ axis is horizontal and points northward, and the $z$ axis is vertical and points downward. The $x y$ plane is taken to correspond to the plane on which the magnetic observations have been made or to which 
INTERNAL MAGNETIZATION OF SEAMOUNTS AND ITS COMPUTER CALCULATION

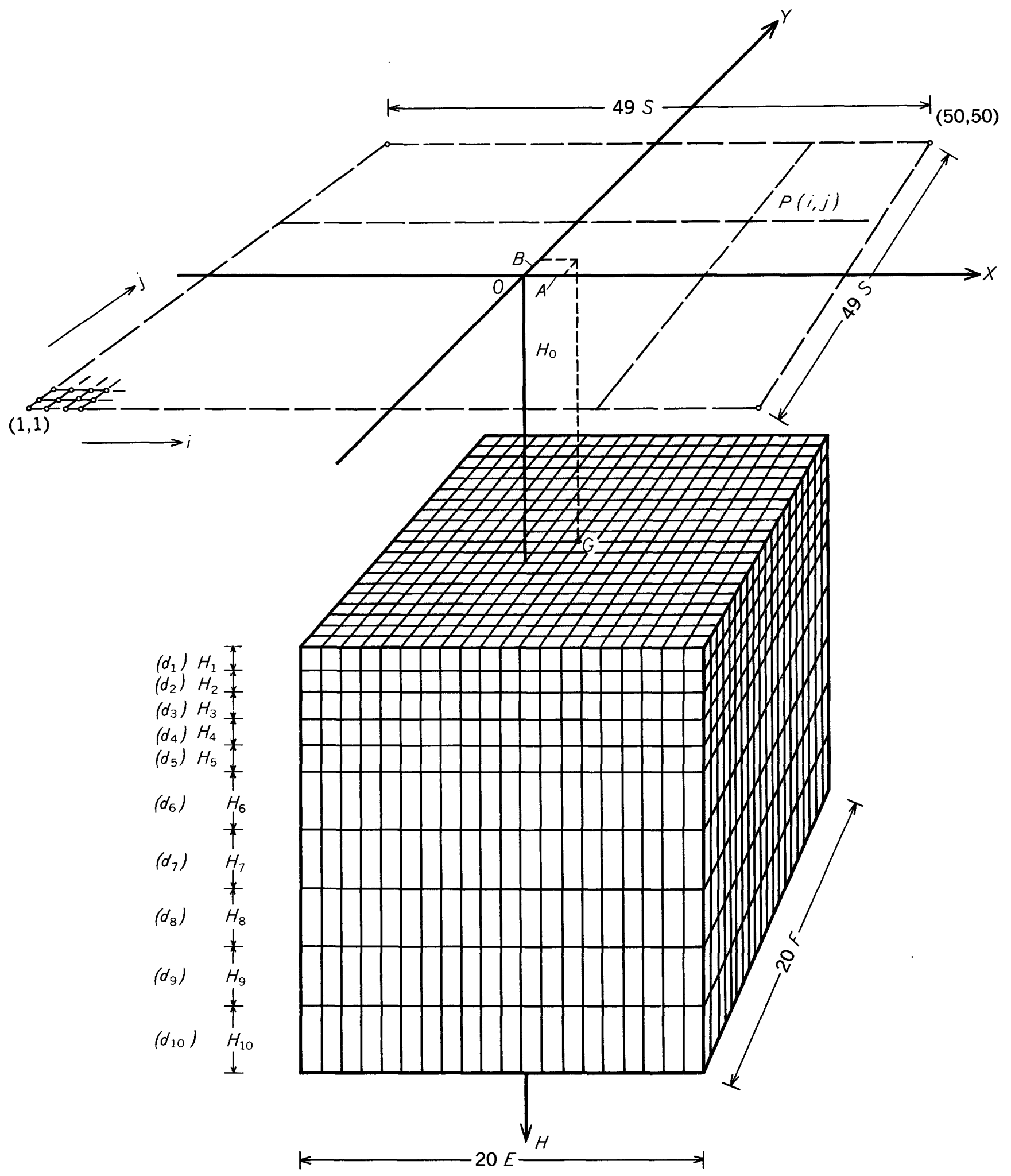

Figure 2.-Grid of stations and prism array. 


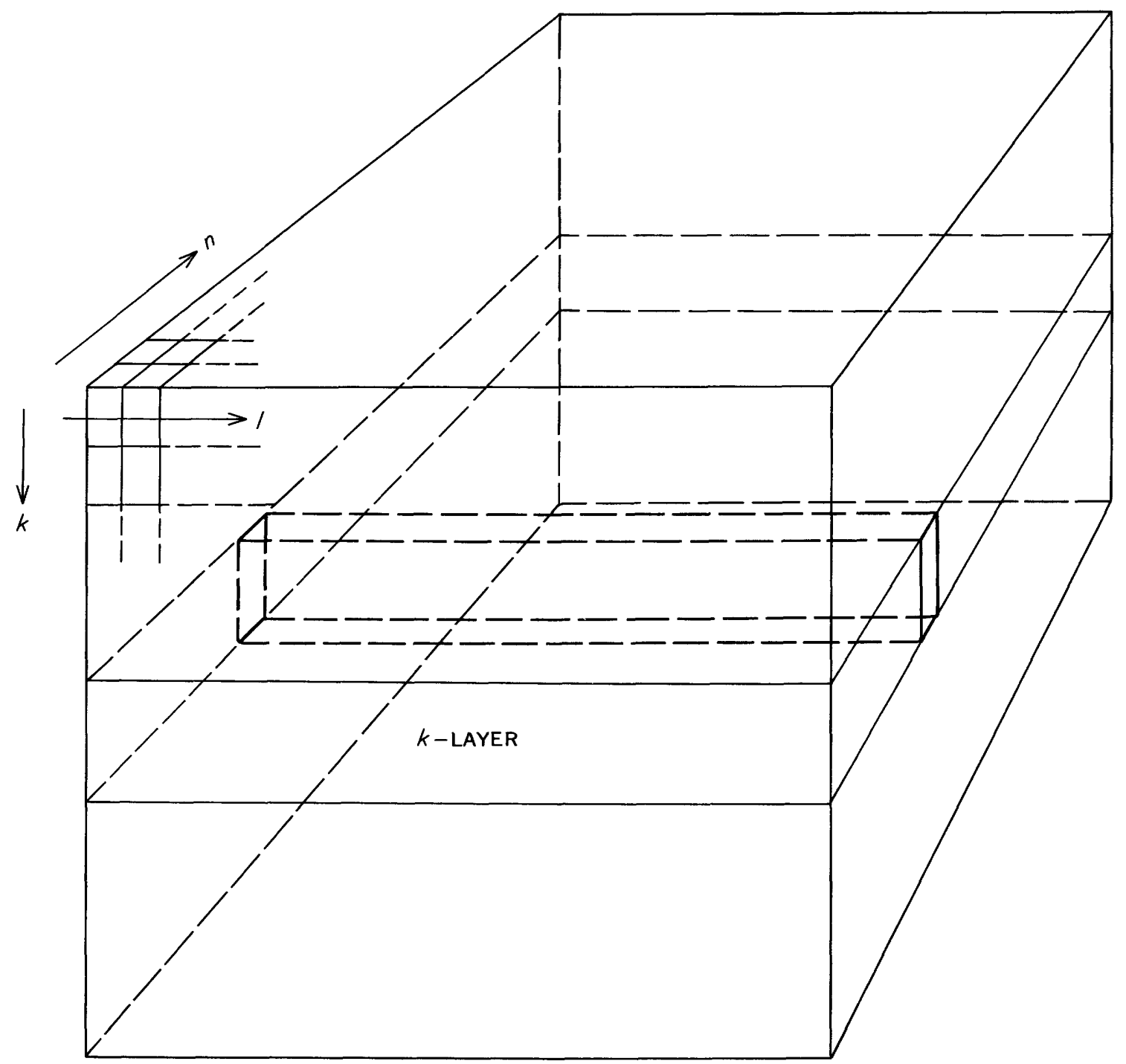

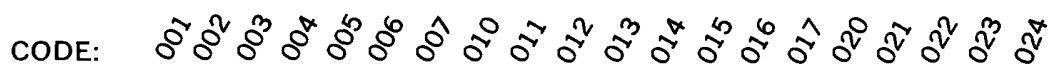

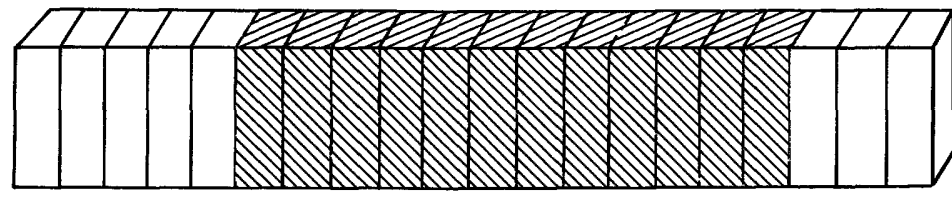

Row $k, n$

$\left(V_{1}\right)$

$\left(W_{1}\right)$

EXAMPLE:

$V_{1} W_{1}=006021$

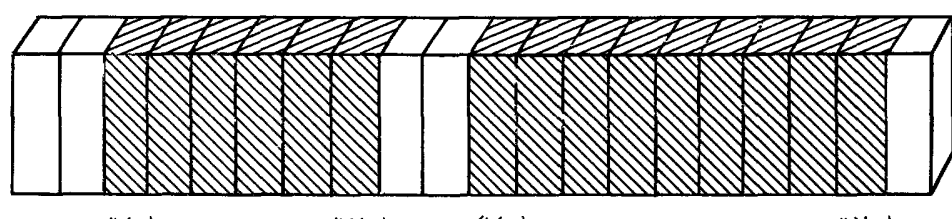

$\left(V_{1}\right)$

$\left(W_{1}\right)$

$\left(V_{2}\right)$

$\left(W_{2}\right)$

EXAMPLE:

$V_{1} W_{1} V_{2} W_{2}=003010013023$

Figure 3.-Prism array and mass description in row. 
they have been reduced. Although this system of coordinates is left handed, we have chosen it because this system avoids coding negative depths and because we preferred to lay out the $x$ axis and $y$ axis parallel to the east and north directions, respectively.

\section{THE FIFLD OF THE FLEMENTARY PRISM}

To calculate the potential of the rectangular prism, the potential expansion in spherical harmonics $H_{n}$ expressed in rectangular coordinates can be used, namely

$$
U=\sum_{n=0}^{\infty} H_{n}=\sum_{n=0}^{\infty} \frac{1}{\rho^{(2 n+1)}} \iiint_{(0)} d h_{n} d \xi d \eta d \zeta
$$

where $h_{n}$ is a homogeneous polynomial of degree $n$ in $x, y$, and $z ; \rho$ is the radial distance to the origin; and $d$ is the density (Kellogg, 1929, p. 135). Here $H_{n}$ is not to be confused with $H_{k}$, which is used later in this paper to designate the thickness of the $k$-layer of an array of prisms. By using the potential expansion and not merely the point-mass approximation, the prisms may have a relatively large size, which thereby decreases the number of prisms required and the computation expense without introducing serious errors.

The expansion of the potential of a point mass or charge in powers or inverse powers of the distance is well known in mathematical physics and geophysics. For example, Grant (1952) used it to interpret gravity data. He uses "reduced $2^{l}$-pole moments," to determine approximately the size and shape of a threedimensional mass distribution required to produce a given gravitational field.

As the degree of symmetry of a body increases, an increasing number of the harmonics are equal to zero. We may start by considering a body of arbitrary shape and then successively specialize its form. The more lower order harmonics there are that are equal to zero, the more accurate is an approximation using only the first ones which are not.

In table 1 is summarized the situation for the first five harmonics, namely $H_{0}-H_{4}$. The first harmonic is simply equal to $M / \rho$; that is, the mass divided by the radial distance to the origin. The second harmonic, namely $H_{1}$, is zero when the origin is at the center

TABLE 1.-Spherical harmonics and specialization of the body

\begin{tabular}{|c|c|c|c|c|c|}
\hline & $H_{0}$ & $H_{1}$ & $H_{2}$ & $\mathrm{H}_{3}$ & $\boldsymbol{H}_{4}$ \\
\hline Arbitrary body and arbitrary origin & $M / \rho$ & $\neq 0$ & $\neq 0$ & $\neq 0$ & $\neq 0$ \\
\hline $\begin{array}{l}\text { gravity } \\
\text { Rectangular symmetry and origin at }\end{array}$ & $M / \rho$ & 0 & $\neq 0$ & $\neq 0$ & $\neq 0$ \\
\hline $\begin{array}{l}\text { center of gravity } \\
\text { Cubical symmetry and origin at center }\end{array}$ & $M / p$ & 0 & $\neq 0$ & $\mathbf{0}$ & $\neq 0$ \\
\hline of gravity & $M / \rho$ & 0 & 0 & $\mathbf{0}$ & $\not \neq 0$ \\
\hline
\end{tabular}

of gravity. Moreover, in addition to selecting the origin at the center of gravity, $\mathrm{H}_{2}=0$ if the body has cubical symmetry, and $H_{3}=0$ if the body has rectangular or cubical symmetry.

The mass element used in the program is an homogeneous rectangular prism, for which $H_{0}=M / \rho, H_{1}=$ $H_{3}=0, H_{2} \neq 0$, and $H_{4} \neq 0$. The program calculates $\mathrm{H}_{0}$ and also $\mathrm{H}_{2}$ when certain circumstances indicated below are met. Thereby, the first four harmonics of the series expansion for the homogeneous rectangular prism are in effect included, namely

$$
\begin{aligned}
U=\frac{M}{\rho}+\frac{M}{6 \rho^{5}}\left\{E^{2}\left(2 x^{2}-y^{2}-z^{2}\right)\right. & F^{2}\left(2 y^{2}-x^{2}-z^{2}\right) \\
& \left.+H^{2}\left(2 z^{2}-x^{2}-y^{2}\right)\right\},
\end{aligned}
$$

where $E, F$, and $H$ are the $x, y$, and $z$ dimensions of the prism.

Because the calculation of the third harmonic entails many extra arithmetical operations, it is wise to avoid laying out rectangular prisms for which $E \simeq F \simeq H$, when a cube should be used instead. Furthermore, when a prism is deep or offset enough with respect to a field point, the calculation of the third harmonic is shunted off and thereby falls back to the point-mass approximation. Specifically, it is safe to use the point-mass approximation when $\zeta \geqq 5 \max (E, F, H)$, where $\zeta$ is the depth of the center of the prism.

\section{DETERMINATION OF THE MAGNETIC FIFLD WITH THE GRAVITY SLAVE}

The procedure employed to calculate the magnetic field applying the Gravity Slave program will now be explained because this program basically determines the gravimetric field. The magnetic potential $W$ at a point $P$ corresponding to a magnet of finite dimensions can be expressed, using vector notation, as the sum of a surface and a volume integral (Maxwell, 1904, p. 10, second equation), namely

$$
W=-\int_{(\omega)} \frac{\boldsymbol{J} \cdot \overrightarrow{\boldsymbol{\nu}}_{1}}{r} d \omega+\int_{(v)} \frac{\operatorname{div} \boldsymbol{J}}{r} d v
$$

Here $J$ is the magnetization vector at an interior point $Q$ of the magnet; $\vec{\nu}_{1}$ is a unit vector parallel to the outward normal to the surface element $d \omega ; d v$ is a volume element; $r$ is the distance $Q P$. The surface and volume integrals extend over the surface and volume of the magnet, respectively. The signs in equation 12 are the opposite of those given by Maxwell; by following Kellogg (1929), the potential of the unit-positive magnetic pole is taken in this paper to be $-1 / r$ instead of $+1 / r$. 
As usual in magnetic interpretations it will be assumed that the magnetization is uniform throughout the magnetized region being considered and that the fields produced by different bodies are superposable. When $\boldsymbol{J}$ is uniform, then $\operatorname{div} \boldsymbol{J}=0$, and the potential $W$ reduces to the surface integral in equation 12 . That is, the effect of the magnet or of the region being considered is equivalent to a surface distribution of a density equal to $-\boldsymbol{J} \cdot \vec{\nu}_{1}$.

Let us now draw at some interior point $C$ of the body a small surface $\Delta \omega$, the normal of which forms an angle $\nu$ with the magnetization intensity $J$ (fig. 4). Consider then the elementary volume $\Delta v$ defined by the tube of force drawn through the perimeter of $\Delta \omega$ and by another section $\Delta \omega^{\prime}$ at a point $C^{\prime}$ distant $\Delta s$ from $C$. The external fie'd produced by this volume element is equivalent, from what has been said previously, to the field produced by a pole of strength $\Delta m=J \Delta \omega^{\prime} \cos \nu^{\prime}$ distributed on $\Delta \omega^{\prime}$, and another one $-\Delta m$ distributed on $\Delta \omega$. Hence the magnetic potential $\Delta W$ at a point $P$ distant $r$ from $C$, corresponding to the element $\Delta v$, is

$$
\Delta W=J \frac{\Delta v}{\Delta s}\left(\frac{1}{r+\Delta r}-\frac{1}{r}\right)+\text { higher order terms. }
$$

The potential for the body is obtained by integrating over the volume, namely

$$
W=\int_{(0)} J \frac{\partial}{\partial s^{\prime}}\left(\frac{1}{r}\right) d v .
$$

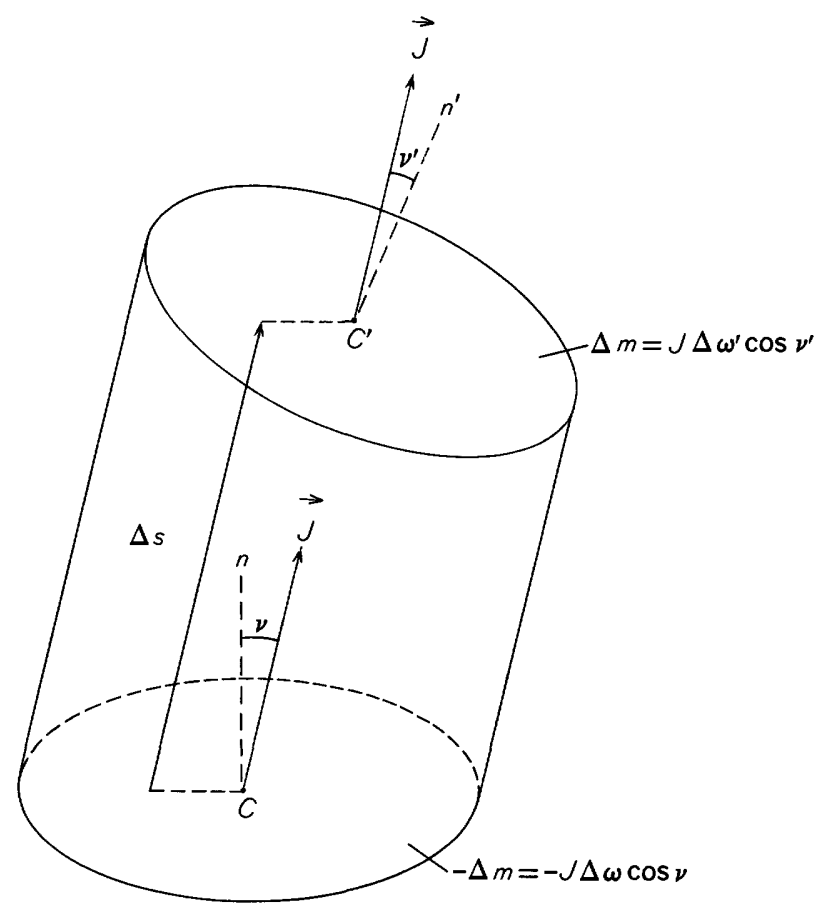

FiguRE 4.--Small magnetized element.
The integration in the previous equation extends over the variables $\xi$, $\eta$, and $\zeta$ corresponding to a point $Q$ of the element $\Delta v$, which may be its center of gravity. On the other hand, the variables $x, y$, and $z$ of the field point $P$ are constant throughout the integration. The operator $\frac{\partial}{\partial s^{\prime}}$ in the integrand involves the coordinates $\xi, \eta$, and $\zeta$, because $\Delta s$ is here an elementary displacement vector of the point $Q$. That is

$$
\frac{\partial}{\partial s^{\prime}}=\frac{J_{x}}{J} \frac{\partial}{\partial \xi}+\frac{J_{y}}{J} \frac{\partial}{\partial \eta}+\frac{J_{z}}{J} \frac{\partial}{\partial \zeta}
$$

where $J_{x} / J, J_{y} / J$, and $J_{z} / J$ are the direction cosines of J. As we have

$$
\frac{\partial}{\partial s}=-\left(\frac{J_{x}}{J} \frac{\partial}{\partial x}+\frac{J_{y}}{J} \frac{\partial}{\partial y}+\frac{J_{z}}{J} \frac{\partial}{\partial z}\right)
$$

then in the derivative $\frac{\partial}{\partial s^{\prime}}\left(\frac{1}{r}\right)$ in the integrand of equation 13 the differentiation can be carried out with respect to the $x, y$, and $z$ variables, instead of $\xi$, $\eta$, and $\zeta$, merely by changing the sign. By so doing, the differentiation operator can be taken outside the integral sign, namely

$$
W=-\frac{\partial}{\partial s} \int_{(v)} J \frac{d v}{r}
$$

The prime index has been dropped, for now the $\partial / \partial s$ operator refers to the $x, y, z$ coordinates.

It is now assumed that the body instead of being magnetized is occupied by a fictitious gravimetric mass distribution of density $J / \gamma$, where $\gamma$ is the universal gravitational constant. The gravimetric potential $U$ of this distribution is

$$
U=\int J \frac{d v}{r}
$$

which, after comparison with equation 16 , gives

$$
W=-\frac{\partial U}{\partial s},
$$

which is known as Poisson's theorem. A relationship similar to equation 18 is valid for any other derivative of the potential because

$$
\frac{\partial W^{n+m+l}}{\partial x^{n} \partial y^{m} \partial z^{l}}=-\frac{\partial}{\partial s} \frac{\partial U^{n+m+l}}{\partial x^{n} \partial y^{m} \partial z^{l}}
$$

which is obtained by successive differentiations of equation 18.

Instead of carrying out analytically the partial differentiation of $U$ with respect to $s$ to obtain $W$, we 
carry it out numerically by means of a finite difference approximation, namely

$$
W \simeq-\left(U_{r+\Delta s}-U_{r}\right) / \Delta s .
$$

Furthermore, by including the divisor $\Delta s$ in the virtual density, namely $d^{\prime}=J /(\gamma \Delta s)$, the magnetic potential becomes

$$
W \simeq U_{r}-U_{r+\Delta s}
$$

With respect to signs, the customary convention in potential theory (Kellogg, 1929, p. 52-53) has been followed; namely, the potential of the unit-positive gravimetric pole is taken as $+1 / r$. That is, in a gravimetric field the potential $U$ is equal to the work function and to the negative of the potential energy. For the magnetic potential $W$ the relations are similar but have opposite signs. Moreover, by considering attraction to be positive, the field intensity is $f=\operatorname{grad} U$ for gravimetric problems, and $f=-\operatorname{grad} W$ for magnetic problems.

At this point the problem needs to be redefined. Let us consider a body $A$ in an $x, y, z$ framework of reference, having a density distribution $d^{\prime}=d^{\prime}(\xi, \eta, \zeta)$. Its gravimetric potential $U\left(x-x_{0}, y-y_{0}, z-z_{0}\right)$, obtained by integration on the $\xi, \eta$, and $\zeta$ coordinates, is known. Some reference point $x_{0}, y_{0}, z_{0}$, fixed to the body, $B$, is taken to represent the position of the body in the coordinate system.

The magnetic potential $W$ corresponding to the body $A$ when magnetized with an intensity $\boldsymbol{J}=\gamma d^{\prime} \boldsymbol{s}_{1}$ where $\boldsymbol{s}_{1}$ is a unit vector parallel to $J$, is given by equation 18 . The $\partial / \partial s$ operator, namely

$$
\frac{\partial}{\partial s}=u_{1} \frac{\partial}{\partial x}+u_{2} \frac{\partial}{\partial y}+u_{3} \frac{\partial}{\partial z}
$$

involves the $x, y$, and $z$ coordinates; that is, it implies shifting the field point. The values $u_{1}, u_{2}$, and $u_{3}$ are the direction cosines of $s_{1}$. If now the $\frac{\partial}{\partial s}$ operator is to involve the $x_{0}, y_{0}, z_{0}$ coordinates-that is, implying a shift of the body as a whole-then

$$
\frac{\partial}{\partial s^{\prime \prime}}=-u_{1} \frac{\partial}{\partial x_{0}}-u_{2} \frac{\partial}{\partial y_{0}}-u_{3} \frac{\partial}{\partial z_{0}} .
$$

The double prime sign on the $s$ denotes that the differentiation involves $x_{0}, y_{0}$, and $z_{0}$.

As an example, let us consider the calculation of the vertical component of the magnetic intensity, namely

$$
\frac{\partial U}{\partial z}=Z^{\mathrm{grav}} .
$$

Differentiating with respect to $s$ and considering equation 18 , we have

$$
Z^{\mathrm{mag}}=-\frac{\partial W}{\partial z}=\frac{\partial}{\partial s} Z^{\mathrm{grav}} .
$$

If the $\frac{\partial}{\partial s}$ operator is to involve $x_{0}, y_{0}$, and $z_{0}$, then

$$
Z^{\mathrm{mag}}=-\frac{\partial}{\partial s^{\prime \prime}} Z^{\mathrm{grav}},
$$

or by numerical approximation

$$
Z^{\mathrm{mag}} \simeq Z_{r}^{\mathrm{grav}}-Z_{r+\Delta s}^{\text {grav }}
$$

In summary, if some kind of a device or software is available which can provide a gravinetric quantity such as the potential or one of its derivatives, the procedure to obtain the similar magnetic quantity is as follows: A fictitious mass is assumed of density $d^{\prime}=J /(\gamma \Delta s)$ occupying similar volune and position as those of the magnetized body. Then two positions, say 1 and 2, of the fictitious mass are considered, one being displaced $-\Delta s / 2$ and the other $+\Delta s / 2$ with respect to the true position. The desired magnetic quantity is the value of the similar gravimetric quantity for position 1 minus its value for position 2. The displacement vector $\Delta s$ is chosen parallel to the magnetization $J$. For the magnitude of $\Delta s$ a small value should be chosen, so that the variation of the geometry because of the shift is negligible and yet sufficiently large so the device can still sense with adequate accuracy the corresponding variation of the quantity. A digital computer is a most suitable device for such a purpose because of its high precision.

If all the quantities are measured in the cgs systen, the magnetic anomaly will be given in oersteds, which can be converted to gammas by multiplying by $10^{5}$. But a scaling factor of $10^{5}$ is already built into the Gravity Slave program because all the lengths in the input data are to be given in meters, and the results produced by the progranı are in milligals instead of gals. Hence, if the cgs systen is used in the calculation of the virtual density and all the lengths in the input data are given in meters, then the Gravity Slave for nuagnetic problenis gives the answers in ganimas.

\section{BIASED-FIEID ANOMALY}

At this point I will introduce the concept of biasedfield anomaly. Let us assume that the anonialy field $f$ produced by the body $V$ is immersed in a field $\vec{\Omega}$ of the same nature, but of constant intensity and direction which acts as a bias (fig. 5). The definition of the biased-field anomaly is

$$
\Lambda=|\vec{\Omega}+\boldsymbol{f}|-\Omega
$$

from which is obtained 


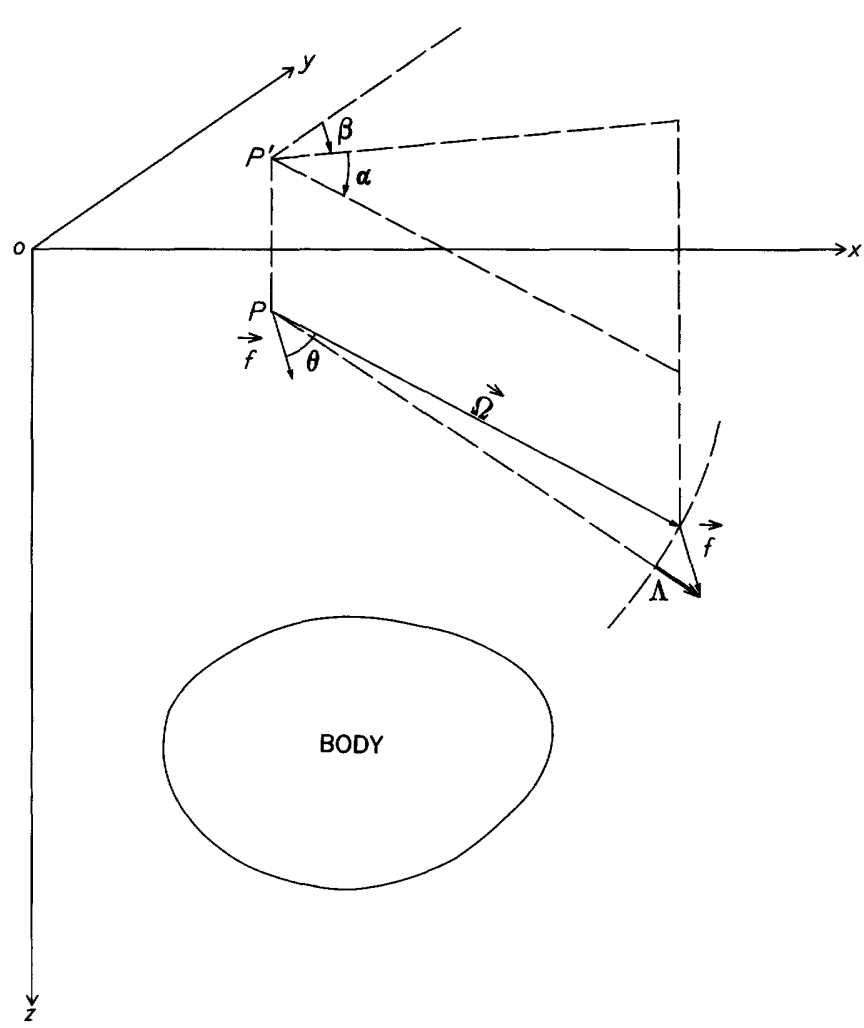

FigURE 5.-Biased-field anomaly $\Lambda$.

where

$$
\Lambda=\left(\Omega^{2}+f^{2}+2 \Omega f \cos \theta\right)^{1 / 2}-\Omega,
$$

$$
\cos \theta=\left(\Omega_{x} X+\Omega_{y} Y+\Omega_{z} Z\right) /(\Omega f) \text {. }
$$

Here $\theta$ is the angle between $\vec{\Omega}$ and $f$, and $X, Y$, and $Z$ are the components of $\boldsymbol{f}$. The $x, y$, and $z$ direction cosines of $\vec{\Omega}$ are

and

$$
\begin{aligned}
& \Omega_{x} / \Omega=\cos \alpha \sin \beta, \\
& \Omega_{y} / \Omega=\cos \alpha \cos \beta,
\end{aligned}
$$

$$
\Omega_{z} / \Omega=\sin \alpha,
$$

where $\alpha$ is the angle of dip (positive downwards), and $\beta$ is the declination (positive east of north) of $\vec{\Omega}$.

The biased-field anomaly can be readily specialized, becoming equal to several geophysically significant quantities. First, it becomes equal to the component of $f$ parallel to the biasing field $\vec{\Omega}$ when $\Omega$ is large. Second, when $\Omega$ is the geomagnetic intensity, and $\Omega>>f$, the biased-field anomaly $\Lambda$ becomes equal to the total intensity anomaly $\Delta T$ used in aeromagnetic prospecting (Vacquier and others, 1951). This can be seen by expanding in series the first term in equation 27, namely
As $\Omega$ increases,

$$
\Lambda=f \cos \theta+\frac{f^{2}}{2 \Omega}+\ldots
$$

$$
\Lambda \rightarrow f \cos \theta
$$

that is, $\Lambda$ becomes equal to the component of $f$ parallel to $\vec{\Omega}$. Third, the biased-field anomaly becomes equal to $f$ when $\Omega=0$, as can be seen from equation 27 . Finally, when $f$ is not negligible in comparison with $\Omega$, then $\Lambda$ has to be used rather than the approximation

$$
\Delta T=f \cos \theta .
$$

In the computer calculation of the biased-field anomaly $\Lambda$, corresponding to a magnetic problem, it is necessary to retain in memory the total value of each of the components of $f$ for each of the two positions of the fiducial mass. The algorithm built in the program to do this is shown diagrammatically in figure 6 . The quantities $X^{T}, Y^{T}$, and $Z^{T}$, which represent the components of $f$ for the set of prisms, are calculated for positions 1 and 2 of the fiducial mass. The components of the magnetic anomaly field are the differences of these values for the two positions. The program determines the direction cosines of $\Omega$ and $f^{\text {mag }}$, then $\cos \theta$, and finally $\Lambda$.

\section{MAGNETIC FIELD EXPRESSED IN $x, y$, AND $z$ POLARIZATIONS}

Let us consider a small element $\Delta v$ drawn about a point $Q$ and magnetized in a certain $\Delta s$ direction (fig. 7 ). The $x$ component of the magnetic field at a point

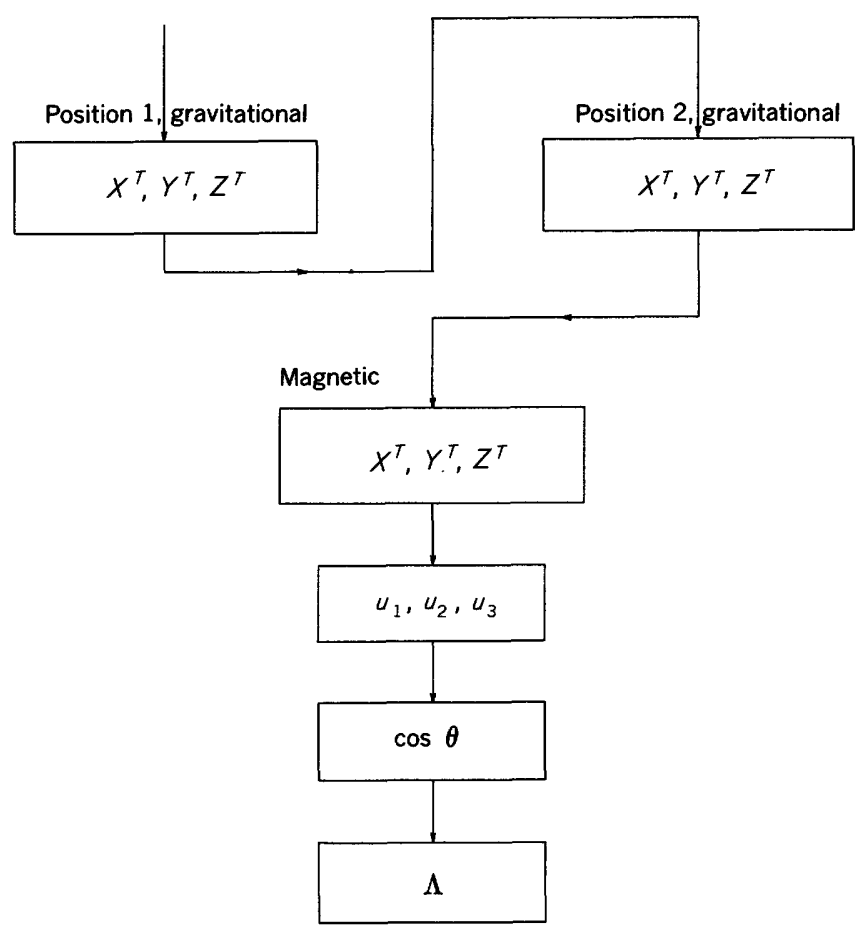

FiguRE 6.-Main steps in the calculation of $\Lambda$. 


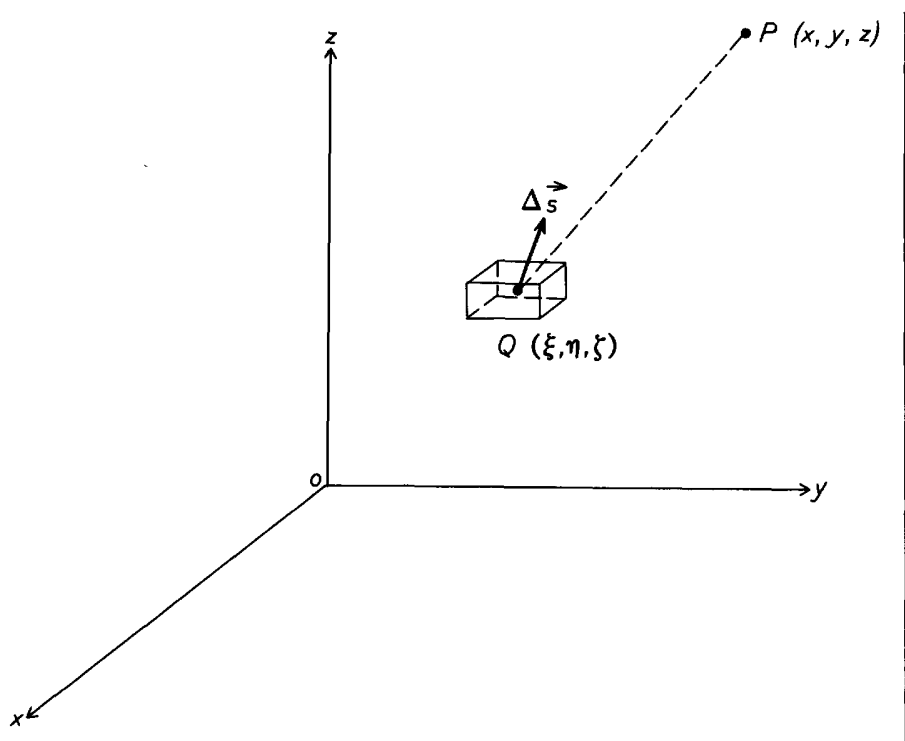

FiguRE 7.-Small magnetized element and system of reference.

$P$, obtained by differentiation in the $\Delta s$ direction of the $x$ component of the gravimetric anomaly, is

$$
X=J \Delta v\left[\frac{u_{1}}{r^{3}}-\frac{3(x-\xi)}{r^{5}}\left\{u_{1}(x-\xi)+u_{2}(y-\eta)+u_{3}(z-\zeta)\right\}\right]
$$

and similarly for the $y$ and $z$ components, where $J$ is the magnetization intensity; $x, y, z$ are the coordinates of $P ; \xi, \eta$, and $\zeta$ those of $Q$; and $u_{1}, u_{2}$, and $u_{3}$ are the direction cosines of $\Delta s$.

If the magnetization $J$ were parallel to the $x$ axis (that is, $u_{1}=1, u_{2}=u_{3}=0$ ), then we would have

$$
\begin{aligned}
& X_{(x)}=J \Delta v\left\{\frac{1}{r^{3}}-\frac{3(x-\xi)^{2}}{r^{5}}\right\}, \\
& Y_{(x)}=-J \Delta v \frac{3(y-\eta)(x-\xi)}{r^{5}},
\end{aligned}
$$

and

$$
Z_{(x)}=-J \Delta v \frac{3(z-\zeta)(x-\xi)}{r^{5}} .
$$

The subscripts $x, y$, and $z$ in parentheses indicate polarization parallel to either the $x, y$, or $z$ axis, respectively. The comparison of equation 31 with equations 32 shows that $X$ is a linear combination of $X_{(x)}, Y_{(x)}$, and $Z_{(x)}$. This relation, together with the similar ones for $Y$ and $Z$, are

$$
\begin{aligned}
& X_{(s)}=u_{1} X_{(x)}+u_{2} X_{(y)}+u_{3} X_{(z)}, \\
& Y_{(s)}=u_{1} Y_{(x)}+u_{2} Y_{(y)}+u_{3} Y_{(z)},
\end{aligned}
$$

and

$$
Z_{(s)}=u_{1} Z_{(x)}+u_{2} Z_{(y)}+u_{3} Z_{(z)} .
$$

The subscript $s$ in parentheses, on the $X, Y$, and $Z$ components on the left side of equations 33, denotes magnetization parallel to $\Delta s$.

Now the biased-field anomaly $\Lambda$ can be expressed in terms of the $x, y$, and $z$ polarizations. When the magnitude of the biasing field $\vec{\Omega}$ is much larger than the magnitude of the anomaly field $f$, the biased-field anomaly reduces to equation 30 , namely

$$
\Lambda=f \cos \theta=\left(\Omega_{x} X_{(s)}+\Omega_{y} Y_{(s)}+\Omega_{z} Z_{(s)}\right) / \Omega .
$$

If instead of one prism, we have a set of $N$ prisms, we have

$$
\Lambda=\left(\Omega_{x} \sum_{n} X_{(s)}^{(n)}+\Omega_{y} \sum_{n} Y_{(s)}^{(n)}+\Omega_{z} \sum_{n} Z_{(s)}^{(n)}\right),
$$

where the superscript $n$ in parentheses denotes the $n$-th prism, thereby we assume that the prisms are numbered $1,2, \ldots, n, \ldots, N$.

As each of the nine components for a prism-namely $X_{(x)}, X_{(y)}, \ldots, Z_{(z)}$-are additive for a set of prisms, so are $X_{(s)}, Y_{(s)}$, and $Z_{(s)}$ which are linear combinations of the first group. Hence each of the summation terms in equation 35 can be expressed in terms of summations of terms corresponding to $x, y$, and $z$ polarizations. By doing this and grouping together the components for each polarization we have

$$
\begin{aligned}
\Lambda= & \frac{u_{1}}{\Omega}\left\{\Omega_{x} \sum_{n} X_{(x)}^{(n)}+\Omega_{y} \sum_{n} Y_{(x)}^{(n)}+\Omega_{z} \sum_{n} Z_{(x)}^{(n)}\right\} \\
& +\frac{u_{2}}{\Omega}\left\{\Omega_{x} \sum_{n} X_{(y)}^{(n)}+\Omega_{y} \sum_{n} Y_{(y)}^{(n)}+\Omega_{z} \sum_{n} Z_{(y)}^{(n)}\right\} \\
+ & \frac{u_{3}}{\Omega}\left\{\Omega_{x} \sum_{n} X_{(z)}^{(n)}+\Omega_{y} \sum_{n} Y_{(x)}^{(n)}+\Omega_{z} \sum_{n} Z_{(z)}^{(n)}\right\}
\end{aligned}
$$

The three quantities within the braces in the above expression are the values attained by $\Lambda$ when there is only $x, y$, or $z$ polarization. Hence

$$
\Lambda=J_{x} \Lambda_{(x)}+J_{y} \Lambda_{(y)}+J_{z} \Lambda_{(z)},
$$

where $\Lambda_{(x)}, \Lambda_{(y)}$, and $\Lambda_{(z)}$ are the values of $\Lambda$ for unit polarizations parallel to the three coordinate axes. It is convenient to define these quantities in terms of a unit polarization, or a reference polarization, because in that way their calculation does not require a previous knowledge of $J$, which is an unknown.

THE TRIPLE-FIELD METHOD OF DETERMINING $J$

Let us now consider the problem of determining the internal magnetization of a given body when its biased-field anomaly $\Lambda_{(s)}$ has been measured at a grid of stations. The biasing vector $\vec{\Omega}$, in this problem the 
geomagnetic intensity, is given. It is assumed, first, that the body is uniformly magnetized throughout, $J$ being the intensity of magnetization.

Let $\bar{\Lambda}^{(v)}$ denote the measured value of $\Lambda^{(v)}$, where the superscript $v$ in parentheses denotes the $v$-th station of the grid. We assume that the stations have been numbered $1,2, \ldots, v, \ldots, \Upsilon$.

The quantity $\Lambda_{(s)}^{(v)}$ should satisfy equation 37 . That is, $\Lambda_{(s)}$ is a linear combination of the $\Lambda_{(x)}, \Lambda_{(y)}$, and $\Lambda_{(z)}$ fields, the values of which can be calculated at each of the stations of the grid from the geometry of the body. Three quantities are unknown-namely $J_{x}, J_{y}$, and $J_{z}$. Hence, if the equation were exactly fulfilled, three observations of $\Lambda$ would be enough to determine the unknowns. But in practice the equation will not be satisfied exactly because of measurement and other kinds of errors. Furthermore, many more than three observations are usually available, which provide more equations than required. These considerations lead to the choice of the method of least squares for determining the three unknowns.

The error at the $v$-th station is

$$
\epsilon_{v}=\bar{\Lambda}^{(v)}-\Lambda_{0}-J_{x} \Lambda_{(x)}^{(v)}-J_{y} \Lambda_{(y)}^{(v)}-J_{2} \Lambda_{(z)}^{(v)} .
$$

It is assumed that in addition to any error at each station there is a datum adjustment $\Lambda_{0}$ to be made on the measured data $\bar{\Lambda}^{(v)}$. The condition of least-squares errors provides four linear equations for the determination of $J_{x}, J_{y}, J_{z}$, and $\Lambda_{0}$, namely

$$
\begin{gathered}
\Lambda_{0} T+J_{x} \sum_{v} \Lambda_{(x)}^{(v)}+J_{y} \sum_{v} \Lambda_{(y)}^{(v)}+J_{z} \sum_{v} \Lambda_{(z)}^{(v)}=\sum_{v} \bar{\Lambda}^{(v)} \\
\Lambda_{0} \sum_{v} \Lambda_{(x)}^{(v)}+J_{x} \sum_{v}\left\{\Lambda_{(x)}^{(v)}\right\}^{2}+J_{y} \sum_{v} \Lambda_{(x)}^{(v)} \Lambda_{(y)}^{(v)}+J_{z} \sum_{v} \Lambda_{(x)}^{(v)} \Lambda_{(z)}^{(v)}=\sum_{v} \Lambda_{(x)}^{(v)} \bar{\Lambda}^{(v)} \\
\Lambda_{0} \sum_{v} \Lambda_{(y)}^{(v)}+J_{x} \sum_{v} \Lambda_{(x)}^{(v)} \Lambda_{(y)}^{(v)}+J_{v} \sum_{v}\left\{\Lambda_{(y)}^{(v)}\right\}^{2}+J_{z} \sum_{v} \Lambda_{(y)}^{(v)} \Lambda_{(z)}^{(v)}=\sum_{v} \Lambda_{(y)}^{(v)} \bar{\Lambda}^{(v)} \\
\Lambda_{0} \sum_{v} \Lambda_{(z)}^{(v)}+J_{x} \sum_{v} \Lambda_{(x)}^{(v)} \Lambda_{(z)}^{(v)}+J_{v} \sum_{v} \Lambda_{(y)}^{(v)} \Lambda_{(z)}^{(v)}+J_{z} \sum_{v}\left\{\Lambda_{(z)}^{(v)}\right\}^{2}=\sum_{v} \Lambda_{(z)}^{(v)} \bar{\Lambda}^{(v)} .
\end{gathered}
$$

The magnetization intensity in terms of $J_{x}, J_{y}$, and $J_{z}$, is

$$
J=\left(J_{x}^{2}+J_{y}^{2}+J_{z}^{2}\right)^{1 / 2},
$$

its declination $\delta$ is given by

$$
\tan \delta=J_{x} / J_{y}
$$

and its inclination $i$ is given by

$$
\tan i=J_{z} /\left(J_{x}^{2}+J_{y}^{2}\right)^{1 / 2} .
$$

The procedure can be readily generalized to the case when the body consists of $\sigma$ regions of known form. Each region is assumed to be uniformly magnetized with certain magnetizations $\boldsymbol{J}_{\sigma}$, which may differ both in directions and magnitudes. Let $\Lambda_{(x), \sigma}^{(v)}$ denote the value at the $v$-th station of the biased-field anomaly produced by the $\sigma$-region under the assumption of unit polarization in the $x$ direction, and similarly for $\Lambda_{(y), \sigma}^{(u)}$ and $\Lambda_{(z), \sigma .}^{(v)}$ These values can be obtained by constructing a prism model for each region and by using the computer method previously described to calculate $\Lambda_{(x)}, \Lambda_{(y)}$, and $\Lambda_{(z)}$. There are $3 \sigma+1$ parameters to be determined-namely $\Lambda_{0}$, and $J_{x, 1}, J_{y, 1}$,
$J_{z, 1}, \ldots, J_{x, \sigma}, J_{y, \sigma}$ and $J_{z, \sigma}$. The sum of the squares of the errors is

$$
\begin{aligned}
\Phi=\sum_{v}\left\{\bar{\Lambda}^{(v)}-\Lambda_{0}-\sum_{\sigma}\right. & \left(J_{x, \sigma} \Lambda_{(x), \sigma}^{(v)}\right. \\
& \left.\left.+J_{y, \sigma} \Lambda_{(y), \sigma}^{(v)}+J_{z, \sigma} \Lambda_{(z), \sigma}^{(v)}\right)\right\}^{2}
\end{aligned}
$$

The condition of least-squares errors provides $(3 \sigma+1)$ linear equations for their determination, namely

$$
\begin{aligned}
& \frac{\partial \Phi}{\partial \Lambda_{0}}=0 \\
& \frac{\partial \Phi}{\partial J_{x, 1}}=\frac{\partial \Phi}{\partial J_{y, 1}}=\frac{\partial \Phi}{\partial J_{z, 1}}=0 \\
& \frac{\partial \Phi}{\partial J_{x, \sigma}}=\frac{\partial \Phi}{\partial J_{y, \sigma}}=\frac{\partial \Phi}{\partial J_{z, \sigma}}=0 .
\end{aligned}
$$


TOTAL AND REMANENT MAGNETIZATIONS

The triple-field method gives the total magnetization $\boldsymbol{J}$, which is the sum of the remanent magnetization $\boldsymbol{J}_{n}$ plus the induced magnetization $\overrightarrow{K \Omega}$ (see fig. 8). Hence the determination of the remanent magnetization

$$
J_{n}=J-\overrightarrow{K \Omega}
$$

requires a prior knowledge of $K$.

When $\boldsymbol{J}_{n}$ is of thermoremanent origin, it is parallel to the magnetic field $\vec{\Omega}$ at geologic time $t$, and its magnitude depends on the magnetic minerals present. It is also proportional to $\Omega$ as long as $\Omega$ is not higher than about 1 oersted; the increment $\Delta J_{n}$, for a given increment $\Delta \Omega$, decreases gradually with increasing $\Omega$. The ratio $Q_{n}=J_{n} /(K \Omega)$ is usually different from 1 and frequently higher than 10, sometimes exceeding 100 ( $\mathrm{Na}$ gata, 1953). Hence $K \Omega$ is not always negligible in comparison of $J_{n}$.

Now let us examine what information can be gleaned about $J_{n}$ and $Q_{n}$ when viewed as functions of $K$, the quantities $J$ and $\vec{\Omega}$ being given. The magnitude of $J_{n}$, deduced from equation 45 , is

$$
J_{n}=\left(J^{2}+K^{2} \Omega^{2}-2 K \Omega J \cos \omega\right)^{1 / 2} .
$$

Here $\omega$ is the angle between $\vec{\Omega}$ and $J$, given by

$$
\cos \omega=\left(u_{1} \Omega_{x}+u_{2} \Omega_{y}+u_{3} \Omega_{z}\right) / \Omega,
$$

where $\Omega_{x} / \Omega, \Omega_{y} / \Omega$, and $\Omega_{z} / \Omega$, and $u_{1}, u_{2}$, and $u_{3}$ are the direction cosines of $\vec{\Omega}$ and $\boldsymbol{J}$, respectively.

The function $J_{n}$ reaches the minimum value

$$
\left(J_{n}\right)_{\min }=J \sin \omega
$$

for $K=K_{1}=(J / \Omega) \cos \omega$, and the function $Q_{n}=J_{n} /(K \Omega)$ reaches the minimum value

$$
\left(Q_{n}\right)_{\mathrm{m} \ln }=\sin \omega
$$

for $K=K_{2}=J /(\Omega \cos \omega)$. These minimums are obtained from the equations $d J_{n}^{2} / d K=0$ and $d Q_{n}^{2} / d K=0$ because the squares of $J_{n}$ and $Q_{n}$ are minimized concurrently with $J_{n}$ and $Q_{n}$.

It may be possible, by considering petrologic information or magnetic measurements on samples, to set limits for the range of likely values of $K$, namely

$$
0<K_{a} \leq K \leq K_{b}
$$

The value of $K$ which enters in the anomaly analysis described in this paper is some sort of an average for
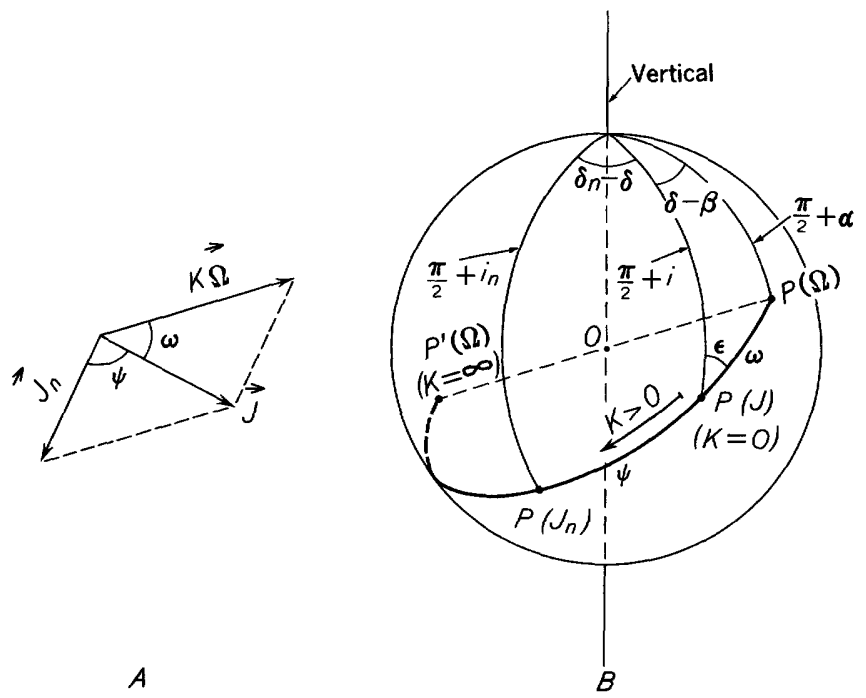

Figure 8.-Relations between $\boldsymbol{J}, \boldsymbol{K} \vec{\Omega}$, and $\boldsymbol{J}_{n}$, when $\delta-\beta<180^{\circ}$ and $\boldsymbol{J}$ is east of $\vec{\Omega}$.

the geologic body. Hence, the range of likely values of this $K$ should be narrower, because of the averaging, than the range when $K$ refers to small samples of rock.

By considering the functional form of $J_{n}$ and $Q_{n}$ and relation 50, we can set upper limits for $J_{n}$ and $Q_{n}$. These depend on the relationships of $K_{1}$ and $K_{2}$ with respect to $K_{a}$ and $K_{b}$. If

then

and

$$
K_{b} \leq K_{1} \text {, }
$$

$$
J_{n} \leq\left(J^{2}+K_{a}^{2} \Omega^{2}-2 K_{a} J \cos \omega\right)^{1 / 2}
$$

$$
Q_{n} \leq\left(1+\frac{J^{2}}{K_{a}^{2} \Omega^{2}}-\frac{2 J \cos \omega}{K_{a} \Omega}\right)^{1 / 2}
$$

On the other hand, if

then

$$
K_{b}>K_{1},
$$

$$
\begin{gathered}
J_{n} \leq\left(J^{2}+K_{b}^{2} \Omega^{2}-2 K_{b} J \cos \omega\right)^{1 / 2} \\
\frac{1}{2}\left(K_{a}+K_{b}\right)>K_{1},
\end{gathered}
$$

when

and

when

$$
J_{n} \leq\left(J^{2}+K_{a}^{2} \Omega^{2}-2 K_{a} J \cos \omega\right)^{1 / 2}
$$

$$
\frac{1}{2}\left(K_{a}+K_{b}\right)<K_{\mathrm{l}} .
$$

As for $Q_{n}$, also when $K_{b}>K_{1}$, we have

$$
Q_{n} \leq\left(1+\frac{J^{2}}{K_{b}^{2} \Omega^{2}}-\frac{2 J \cos \omega}{K_{b} \Omega}\right)^{1 / 2}<1
$$

or

$$
Q_{n} \leq\left(1+\frac{J^{2}}{K_{a}^{2} \Omega^{2}}-\frac{2 J \cos \omega}{K_{a} \Omega}\right)^{1 / 2},
$$

whichever is smaller. 
Now let us study the direction of $J_{n}$ using the unit sphere. In figure 8 , the points $P(\Omega), P(J)$, and $P\left(J_{n}\right)$ represent the directions of $\vec{\Omega}, J$, and $J_{n}$, respectively. The inclination $i_{n}$ and the declination $\delta_{n}$ of $J_{n}$ are given by

$$
\sin i_{n}=\cos \psi \sin i+\sin \psi \cos i \cos \epsilon
$$

and

$$
\sin \left(\delta_{n}-\delta\right)=\frac{\sin \psi \cos \alpha \sin (\delta-\beta)}{\sin \omega \cos i_{n}},
$$

where $\alpha$ and $\beta$ are the inclination and declination of $\vec{\Omega}$, $i$ and $\delta$ are the inclination and declination of $J$, and $\epsilon$ is given by

$$
\sin \epsilon=\frac{\sin (\delta-\beta) \cos \alpha}{\sin \omega}
$$

and

$$
\sin \psi=\frac{K \Omega \sin \omega}{J_{n}}
$$

With the previous formulas, $J_{n}$ and $Q_{n}$ can be calculated for given values of $K$ or limits established to their admissible values.

\section{INPUT AND OUTPUT OF THE PROGRAM}

The different capabilities of the program are controlled by a simple metalanguage consisting of eight mnemonic statements. The name of each statement defines the capability referred to, and an accompanying number indicates what to do about it. The statements and the values of the parameters are recorded in symbolic cards, that are loaded into the computer together with the program deck. The input data consist of (a) description and position of the mass distribution in terms of the scheme of prism arrays previously described and (b) magnitude, inclination, and declination of the biasing field. Also, in magnetic problems, the parameters $A, B, H_{0}$ corresponding to the two assumed positions of the set of prism arrays have to be given. The shifting of the virtual mass is accomplished simply by ordering the program to compute the gravity effect for positions 1 and 2 and then by subtracting the effect for position 2 from that for position 1 . The results are printed as maps, under the full command of the program, on an on-line or off-line printer.

\section{THE MAGNETIZATIONS OF MAHER, BOUTELLE, AND HOKE SEAMOUNTS \\ THE SETTING OF MAHER, BOUTELLE, AND HOKE SEAMOUNTS}

As an illustration, I have applied the triple-field method to Maher, Boutelle, and Hoke Seamounts in the northeastern Pacific Ocean. These seamounts were selected after examining bathymetric and magnetic niaps at Scripps Institution of Oceanography. The determination of their directions of internal magnetization may be of significance to the study of several tectonic features of a rather unique character that have been found in the area where they are located.

By studying the bathymetry, Menard (1955) discovered a system of linear belts of faulting which he denotes "fracture zones" (fig. 9). They closely follow arcs of great circles and are known to extend in an approximately east-west direction for $1,400-3,300$ niles, from the western edge of the North American continent to about the longitude of Hawaii. Some of the belts recognized to date are Mendocino, Pioneer, Murray, Molokai, Clarion, and Clipperton. These belts have been compared to the Lüders lines which appear on sheared metals. Menard (1955) believed that they are of Mesozoic to Cenozoic age. On the other hand, Vacquier, Raff, and Warren (1961) believed that the Mendocino, Pioneer, and Murray fault belts have been quiescent since some time in the Paleozoic.

An appreciable change of the regional depth of the ocean floor occurs at the Mendocino and Murray fracture zones. South of the Mendocino fracture zone

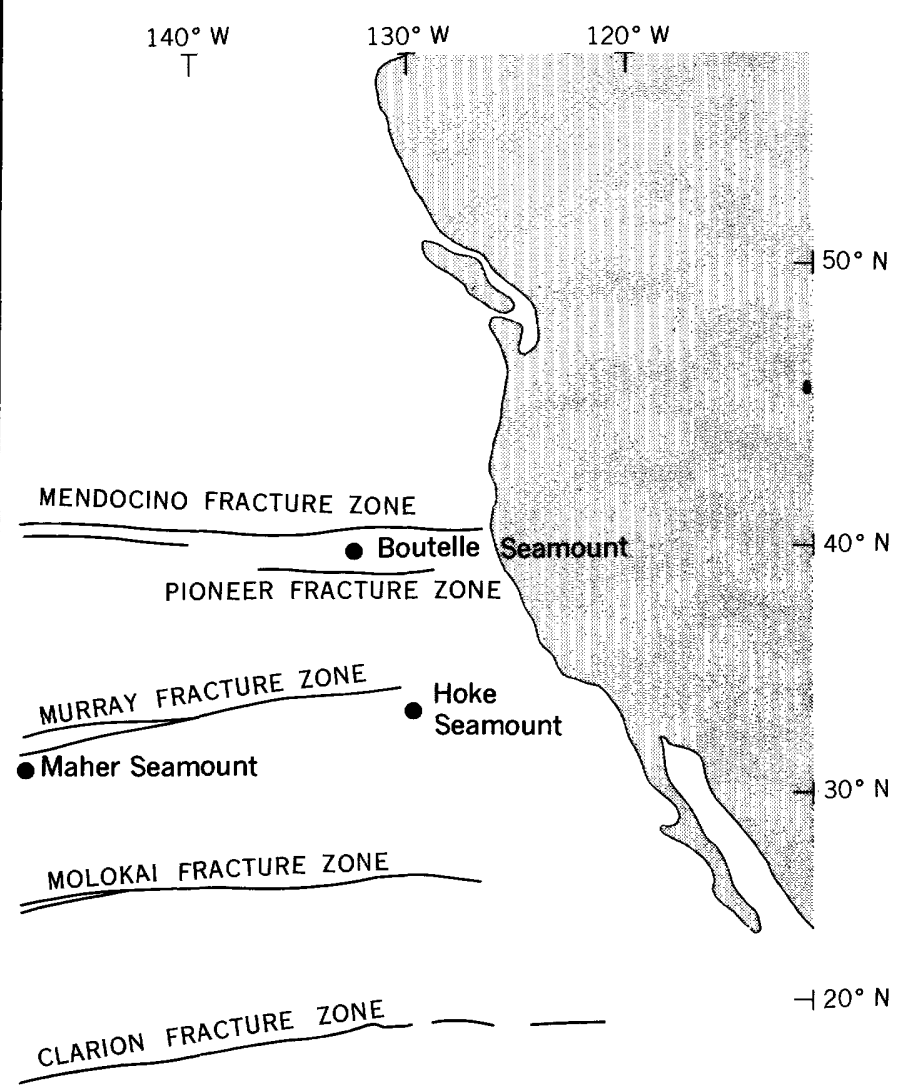

Figure 9.-Fracture zones and locations of Maher, Boutelle, and Hoke Seamounts. From "Marine Geology of the Pacific" by H. W. Menard. Copyright 1964 by McGrawHill Book Co. Used by permission. 
the sea floor is about one-half mile deeper than to the north, and north of the Murray fracture zone it is about one-quarter mile deeper than to the south.

Furthermore, a remarkable pattern of magnetic anomalies-in the form of virtually linear, alternately positive and negative anomalies-has been discovered (Mason, 1958; Mason and Raff, 1961; Menard and Vacquier, 1958). These anomalies extend in an approximately north-south direction, maintaining a great regularity of direction and character between the major fracture zones. They have amplitudes of up to several hundred gammas and a ridge-to-ridge distance of about 10-20 miles. Anomalies with a similar regularity of pattern and covering areas as large have not been discovered in any continental area. The linear anomalies probably extend over wider areas of the Pacific than established until now. Their existence recently has been demonstrated by the U.S. Coast and Geodetic Survey in the north Pacific, south of the Alaska trench (Peter and Stewart, 1965).

The pattern of the nugnetics is clearly offset along some of the fracture zones, a condition suggesting a relative displacement of the two bounding crustal blocks. Because of the constancy of their shape along the linear trend, the anomalies can be correlated across the fracture zones (Menard and Vacquier, 1958; Vacquier and others, 1961; Vacquier, 1962a). Thereby Vacquier, Raff, and Warren (1961) conclude that there is left-lateral displacement of about $1,160 \mathrm{~km}$ across the Mendocino fracture zone, a left-lateral displacement of about $265 \mathrm{~km}$ across the Pioneer fracture zone, and a right-lateral displacement of about $154 \mathrm{~km}$ across the Murray fracture zone. A subsequent survey along the Murray fracture zone (Raff, 1962) revealed that the displacement varies along the fracture zone and at places may be as nuch as $630 \mathrm{~km}$.

As for the origin of the magnetic pattern, which is important for the study of the seamounts and their magnetizations, two possibilities may be explored: (a) the pattern was formed after the oceanic crust came into existence or (b) the pattern and the oceanic crust or a certain layer of it originated at about the same time. In line with the first possibility, three alternatives have been proposed (Mason and Raff, 1961; Raff and Mason, 1961; Bullard and Mason, 1963) about the bodies causing the magnetic patternnamely, (a) isolated bodies of magnetic materials within the "second layer," (b) block faulting of the main crustal layer, and (c) intrusions of magnetic material.

Along this first line of thought, the sequence of najor events could have been as follows: The initial deformation, which defined the locations of the anonialies, could have been either fracturing or folding by buckling of the oceanic crust. Because of the regularity of the pattern, the oceanic crust should have been very uniform mechanically at the time of the initial deformation, and the causative stresses should have been uniform over the wide areas involved. The evidence about the age of this initial deformation is indefinite. It could have taken place any time before the Mesozoic or early Cenozoic and as far back as the Precambrian. If the cause of the nuagnetic anomalies is not merely block faulting of the nuain crustal layer, then either magnetic material (a) was intruded into the second layer, (b) extruded at some time during the deposition of the sedimentary components of the second layer, or (c) extruded on the first sedimentary layer. Submarine volcanoes could have been formed during this period of volcanic activity. Next, the fracture zones would have appeared, with the horizontal displacement beginning some time after the shear fracturing of the crust.

Recently Vine and Matthews (1963) proposed the ingenious hypothesis that the magnetic pattern and the main oceanic crustal layer originated together. This layer (seismic layer 3) would have been formed above the center of an oceanic ridge by some kind of segregation of nuantle material, spreading laterally by the drag of an underlying convection current. Furthermore, they assumed that at the time the layer was being formed the magnetic field was reversing periodically, and thus the newly created crust acquired nuagnetization in strips of alternating directions as it spread away from the oceanic ridge.

The structural role of the fracture zones, when the Vine-Matthews spreading-floor hypothesis is accepted, becones clear with the concept of transform fault introduced by Wilson (1965a, b, c). Transform faults would exist where the crust is absorbed into the interior and formed elsewhere and thus would explain the abrupt ending of many dislocations. Yet the offsets of the midoceanic ridges (Menard, 1960; Heezen, 1962) would be merely an expression of the shape of the initial crustal breaks and not the result of strike-slip faulting.

Talwani, Le Pichon, and Heirtzler (1965) and Vine and Wilson (1965) have further elaborated on the Vine-Matthews hypothesis. According to their views, the magnetic anomalies would be genetically related to the forniation of the midocean ridge system in a manner that the magnitude of the anomaly at a given location would depend on the distance to the ridge axis. Hence, the anomalies should be symmetrical about the axis, and the pattern should be linear and parallel to it. A preexisting offset of the ridge would cause, with the spreading of the crust, an offset of the magnetic pattern. In the area of the northeast Pacific, Talwani, Le Pichon, and Heirtzler (1965) postulated that the axial area of the East Pacific Rise south of 
the Mendocino fracture zone underlies the Basin and Range province and the Colorado Plateaus.

Maher Seamount ${ }^{1}$ is about 10 miles south of the Murray fracture zone and about 1,350 nautical miles from California (fig. 9). On the U.S. Coast and Geodetic Survey Chart BC-1506N (1955) it is shown as a double-peaked feature centered at about lat $29^{\circ} 30^{\prime} \mathrm{N}$. and long $148^{\circ} 49^{\prime} \mathrm{W}$. Boutelle Seamount ${ }^{2}$ is between the Mendocino and Pioneer fracture zones, about 300 nautical miles offshore (fig. 9). On the U.S. Coast and Geodetic Survey Chart BC-1407 (1953) it is shown at lat $39^{\circ} 1^{\prime} \mathrm{N}$. and long $131^{\circ} 5^{\prime} \mathrm{W}$. Hoke Seamount ${ }^{3}$ is about 100 nautical miles south of the Murray fracture zone and about 310 nautical miles offshore (fig. 9). On the Bureau of Commercial Fisheries Topographic Chart 2 (1964) it is shown at lat $32^{\circ} 8^{\prime} \mathrm{N}$. and long $126^{\circ} 59^{\prime} \mathrm{W}$.

\section{THE COMPUTER CALCULATION OF THE MAGNETIZATION OF MAHER, BOUTELLE, AND HOKE SEAMOUNTS}

For each of three seamounts-Maher, Boutelle, and Hoke- a model was built with rectangular prisms defined by prism arrays in the manner described in this paper. For each seamount the bathymetry obtained from Scripps Institution of Oceanography charts differs somewhat from that given in the published charts mentioned above. To construct a model, the seamount is sliced by a number of horizontal planes at elevations which correspond to given contour lines. Each slice is then approximated by an assembly of rectangular prisms with their top and bottom horizontal faces on the upper and lower planes defining the slice. The prism faces parallel to the $x$ and $y$ directions were set parallel to the magnetic east and magnetic north directions. The number of prisms per layer decreases upwards from layer to layer because of the shape of the seamounts. In this manner a staircase surface was constructed closely matching the actual surface.

Because of the shape of the seamounts, most of the prisms used are nearly flat. For example, for Maher Seamount some prisms are $183 \mathrm{~m}$ (100 fathoms) high in comparison to a horizontal dimension of $2,000 \mathrm{~m}$. The shallowest of these lies with its top surface at a depth of $3,109 \mathrm{~m}$ (1,700 fathoms) below the plane of stations. That is, all locations where field values are calculated lie on or beyond a sphere of radius equal to 2.26 times the radius of the minimum enclosing sphere

\footnotetext{
Named after Captain T. J. Maher, Commanding Officer of the U.S. Coast and Geodetic Survey ship Guide. In 1927 he surveyed seamounts off the Hawaiian Islands.

2 Named after Charles O. Boutelle, an Assistant in the U.S. Coast and Geodetic Survey in the 19th century. He worked on geodetic surveys, tides, and currents.

${ }^{3}$ Named after William E. Hoke, inventor of a system of navigation to providecompass corrections. He died in the 1920's.
}

of the prism. Yet for horizontally flat prisms, the percentage of error of the approximation scheme used is admissible even when the field locations are on a sphere of radius as small as about 0.5 of that of the minimum enclosing sphere.

For the calculation of the hypothetical fields, the following values were taken: $J=5 \times 10^{-4}$ in cgs units, which corresponds to $\Omega=0.5$ oersted, and $K=0.001$ in cgs units; $\gamma=6.67 \times 10^{-8}$ in cgs units; and $\Delta s=1,000 \mathrm{~cm}$. This gives $d^{\prime}=J /(\gamma \Delta s)=75$ in cgs units. The values of $\Omega$ indicated in plates $1-3$ are the actual values of the geomagnetic intensity at the corresponding locations.

Values of the total-intensity anomaly (the biasedfield anomaly in the theoretical part of this paper) were calculated for a grid of $16 \times 16$ stations centered over the model of each seamount, with a unit spacing $S=4,000 \mathrm{~m}$ in Maher and Hoke Seamounts and $S=8,000 \mathrm{~m}$ in Boutelle Seamount. The calculation, in an IBM-704 computer, of the four hypothetical fields-that is, for polarizations parallel to the magnetic north, magnetic east, vertical and to the present geomagnetic field-required 43,56 , and 30 minutes for Maher, Boutelle, and Hoke Seamounts, respectively. The magnetic anomalies over the three seamounts, which are used in this paper, were measured with total-field flux-gate magnetometers by ships of the Scripps Institution of Oceanography. Regional effects and short-time fluctuations have been removed.

Maher Seamount (pl. 1A) is about $30 \mathrm{~km}$ long and $12 \mathrm{~km}$ wide and rises about 600 fathoms above the ocean floor. Its model contains 73 rectangular prisms (pl. $1 B$ ). As for horizontal prism dimensions, three sizes were chosen: $2,000 \times 2,000 \mathrm{~m}, 2,000 \times 4,000 \mathrm{~m}$, and $4,000 \times 4,000 \mathrm{~m}$. The prisms occupy positions in six layers bounded by seven datum planes-namely 2,300 , $2,200, \ldots$, and 1,700 fathoms.

A simple comparison of the hypothetical and observed anomalies gives a first qualitative understanding of the manner of magnetization of the seamounts. The hypothetical anomalies for Maher Seamount, shown in plate $1 C-F$, should be compared with the observed anomaly (pl. $1 H)$. Plate $1 G$ corresponds to a least-squares fitted field for Maher Seamount, which will be discussed later. The fact that the range of values for the observed anomaly is wider than for the hypothetical anomaly indicates that the apparent susceptibility is larger than the value $K=0.001$ in cgs units taken for the model. Because the shape of the observed anomaly (pl. $1 H$ ) is different when a magnetization parallel to the present geomagnetic field is assumed (pl. $1 F)$, the direction of $\boldsymbol{J}$ should differ substantially from that of $\vec{\Omega}$. On the other hand, the observed and the east-magnetization anomalies, parts $H$ and $E$ of 
plate 1 , respectively, are more similar. Hence, in Maher Seamount the internal magnetization should have a strong magnetic-east component. Yet, no linear combination of the anomalies calculated, with the model assumed, can explain the sharp troughs on the north and south sides of the seamount.

Boutelle Seamount (pl. $2 A$ ) is ovallike, about $42 \mathrm{~km}$ long and $22 \mathrm{~km}$ wide; it rises about 1,400 fathoms above the ocean floor and reaches within about 900 fathoms of the surface. Its model (pl. 2B) contains 100 prisms. As for horizontal prism dimensions, the following sizes were chosen : $1,000 \times 1,000 \mathrm{~m}, 2,000 \times 2,000 \mathrm{~m}, 4,000 \times$ $4,000 \mathrm{~m}$, and $8,000 \times 8,000 \mathrm{~m}$. The prisms occupy positions in seven layers bounded by eight datum planes-namely $2,300,2,100, \ldots, 1,100$, and 900 fathoms.

The hypothetical anomalies for Boutelle Seamount are shown in plate $2 C-F$. Plate $2 G$ corresponds to the optimum-fit field, to be discussed later. The trough to the southwest of the seamount, in the observed anomaly (pl. $2 H$ ), is more pronounced than that to the northwest, yet the opposite occurs when the magnetization is parallel to the present field (pl. $2 F$ ). This means that $\boldsymbol{J}$ has an appreciable southwest component.

Hoke Seamount (pl. $3 A$ ) is conelike, is about $20 \mathrm{~km}$ in diameter, rises about 1,500 fathoms above the ocean floor, and reaches within about 700 fathoms from the surface. Its model contains 67 prisms. As for horizontal prism dimensions the following sizes were chosen: $2,000 \times 2,000 \mathrm{~m}, 2,000 \times 4,000 \mathrm{~m}, 4,000 \times 4,000 \mathrm{~m}$, and $8,000 \times 8,000 \mathrm{~m}$. The prisms occupy positions in eight layers bounded by nine datum planes-namely 700, $800,1,000,1,200, \ldots$. , and 2,200 fathoms.

The situation for Hoke Seamount is presented in plate $3 B-E, G$. Plate $3 F$ corresponds to the optimumfit field, to be discussed later. Judging by the range of values, the apparent susceptibility of this seamount is about eight times the value $K=0.001$ in $\mathrm{cgs}$ units taken for the model. Because the observed magnetic high is about $5 \mathrm{~km}$ southward of its position when the magnetization is parallel to the present field, the angle of inclination of $\boldsymbol{J}$ should be smaller than that of $\vec{\Omega}$, but both these vectors should have about the same declination.

Subsequently, the internal magnetizations of Maher, Boutelle, and Hoke Seamounts were calculated with the triple-field method for arrays of 69, 57, and 64 fitting points, respectively. The boundaries of these arrays are shown with segmented lines in the figures. A Burroughs B220 program for multiple regression analysis was used for this calculation.

Several factors had to be considered in laying out these grids. Obviously they could not extend much beyond the area defined by the actual observations. Main highs and lows of the hypothetical and observed anomalies were to be included, whereas effects clearly attributable to neighboring anomalies were to be omitted. The fitting points were selected for each seamount from among the stations at which the three hypothetical anomalies had been calculated; thus the need for interpolation was avoided. In the contour map of the observed anomaly, the value was read off at each fitting point.

For Hoke Seamount the laying out of the grid offered no difficulty, for its anomaly is distinct and well isolated (pl. $3 G$ ). For Boutelle it is difficult to leave aside the effect of the extraneous anomalies which appear to the northeast and southwest of the seamount (pl. $2 H$ ), and the grid had to be trimmed in these two directions. The difficulty is greater for Maher Seamount because the anomaly apparently merges to the northwest and to the east with other anomalies. The grid chosen (pl. $1 H$ ) is a compromise between the need to leave them out and the need to include essential features attributable to the seamount.

The findings about the internal magnetization are as follows (table 2): The apparent magnetization is 3.85 ,

TABLE 2.-Computer solution of the total magnetization of Maher, Boutelle, and Hoke Seamounts

\begin{tabular}{|c|c|c|c|}
\hline Quantity & $\begin{array}{c}\text { Maher } \\
\text { Seamount }\end{array}$ & $\begin{array}{l}\text { Boutelle } \\
\text { Seamount }\end{array}$ & $\begin{array}{c}\text { Hoke } \\
\text { Seamount }\end{array}$ \\
\hline $\begin{array}{l}J\left(\times 10^{-3} \text { cgs emu }\right) \\
K_{\text {app }}\left(\times 10^{-3} \text { cgs emu }\right) \\
\delta, \text { declination of } J\end{array}$ & $\begin{array}{r}1.89 \\
3.85 \\
91^{\circ} 30^{\prime} \mathrm{E}\end{array}$ & $\begin{array}{r}0.74 \\
1.48 \\
126^{\circ} 15^{\prime} \mathrm{W}\end{array}$ & $\begin{array}{r}3.91 \\
8.32 \\
17^{\circ} 10^{\prime} \mathrm{E} .\end{array}$ \\
\hline $\begin{array}{l}\beta, \text { declination of } \vec{\Omega} \\
i, \text { inclination of } \vec{J}\end{array}$ & $\begin{array}{r}13^{\circ} 50^{\prime} \mathrm{E} \\
+46^{\circ} 15^{\prime}\end{array}$ & $\begin{array}{l}18^{\circ} 50^{\prime} \mathrm{E} \\
+24^{\circ} 30^{\prime}\end{array}$ & $\begin{array}{r}15^{\circ} 40^{\prime} \mathrm{E} \\
+30^{\circ} 55^{\prime}\end{array}$ \\
\hline$a$, inclination of $\vec{\Omega}$ & $+58^{\circ}$ & $+61^{\circ}$ & $+56^{\circ}$ \\
\hline $\begin{array}{l}\omega_{2} \text { angle between } \boldsymbol{J} \text { and } \vec{\Omega} \\
\boldsymbol{K}_{1}\left(\times 10^{-3} \text { cgs emu }\right) \\
\left(\boldsymbol{J}_{n}\right)_{\text {mia }}\left(\times 10^{-3} \mathrm{cgs} \text { emu }\right) \\
\boldsymbol{K}_{2}\left(\times 10^{-3} \mathrm{cgs} \mathrm{emu}\right) \\
\left(\sigma_{n}\right)_{\min }\end{array}$ & $\begin{array}{r}46^{\circ} 20^{\prime} \\
2.66 \\
1.36 \\
5.58 \\
0.72\end{array}$ & $\begin{array}{r}89^{\circ} 55^{\prime} \\
1,485 \\
0.74 \\
1.44 \\
1.00\end{array}$ & $\begin{array}{l}25^{\circ} 5^{\prime} \\
7.53 \\
1.66 \\
9.18 \\
0.42\end{array}$ \\
\hline
\end{tabular}

1.48 , and 8.32 in $10^{-3} \mathrm{cgs}$ units in Maher, Boutelle, and Hoke Seamounts, respectively. For Maher Seamount the computed $\boldsymbol{J}$ has a declination which is rotated about $78^{\circ} \mathrm{E}$. and the inclination about $8^{\circ}$ smaller than for $\vec{\Omega}$. The vector $J$ forms an angle of about $46^{\circ}$ with $\vec{\Omega}$. In Boutelle Seamount $\boldsymbol{J}$ has a declination which is rotated about $145^{\circ} \mathrm{W}$. and an angle of inclination about $37^{\circ}$ smaller than for $\vec{\Omega}$. The vector $\boldsymbol{J}$ forms an angle of about $90^{\circ}$ with $\vec{\Omega}$. In Hoke Seamount $J$ has about the same declination as $\vec{\Omega}$, but its angle of inclination is about $25^{\circ}$ smaller than for $\vec{\Omega}$. Lower limits were calculated for $J_{n}$ and $Q_{n}$ by analyzing the vector relationship between $J, J_{n}$, and $\vec{\Omega}$ as a function of $K$ in 
the manner described in this paper. Taking the results as a group, one sees that the $J_{n}$ cannot be smaller than 0.00074 in cgs units, and the $Q_{n}$ not smaller than 0.42 .

For Hoke Seamount the anomaly obtained by least-squares fitting (pl. $3 F$ ) agrees well in shape, magnitude, and position with the observed one (pl. $3 G$ ). In fact, it gives the best reproduction of the observed field of the three seamounts. For Boutelle Seamount the agreement is reasonably good as to the shape and magnitude of the anomalies (pl. $2 G, H$ ), atthough the calculation gives negative troughs which are not as pronounced as the observed ones. For Maher Seamount the difficulty of isolating the anomaly of the seanount itself impairs the reproduction of the observed field, as can be seen by comparing plates $1 G$ and $1 H$. The sharp troughs on the north and south of the magnetic high are not reproduced. Probably a better result would be obtained for Maher Seamount if the seanlount were assumed to consist of two adjoining bodies, side by side on an east-west direction, and to have different directions of magnetization.

TABLE 3.- $\mathrm{J}_{\mathbf{n}}$ and locus of north virtual pole

\begin{tabular}{|c|c|c|c|c|c|}
\hline$K\left(\times 10^{-3} \mathrm{cgs} \mathrm{emu}\right)$ & $\begin{array}{l}J_{n}\left(\times 10^{-3}\right. \\
\text { cgs emu })\end{array}$ & $\delta_{n}$ & $i_{n}$ & $\phi^{\prime}$ & $\lambda^{\prime}$ \\
\hline \multicolumn{6}{|c|}{ Maher Seamount } \\
\hline $\begin{array}{l}0 \\
0 \\
2.66 \\
4 \\
8\end{array}$ & $\begin{array}{l}1.89 \\
1.40 \\
1.36 \\
1.51 \\
2.95\end{array}$ & $\begin{array}{r}91^{\circ} 30^{\prime} \mathbf{E} . \\
114^{\circ} 30^{\prime} \mathbf{E} . \\
121^{\circ} \mathbf{4 5}, \mathbf{E} \\
1344^{\circ} 5^{\prime} \mathbf{E} \\
158^{\circ} 30^{\prime} \mathbf{E}\end{array}$ & $\begin{array}{l}+46^{\circ} 15^{\prime} \\
+22^{\circ} 20^{\prime} \\
+10^{\circ} 55^{\prime} \\
-11^{\circ} 20^{\prime} \\
-41^{\circ} 40^{\prime}\end{array}$ & $\begin{array}{l}+12^{\circ} \\
-14^{\circ} 50^{\prime} \\
-24^{\circ} 14^{\prime} \\
-41^{\circ} 0^{\prime} \\
-70^{\circ} 5^{\prime}\end{array}$ & $\begin{array}{l}83^{\circ} 55^{\prime} \mathrm{W} \\
81^{\circ 3} 30^{\prime} \mathrm{W} \\
80^{\circ} 5^{\prime} \mathrm{W} \\
78^{3} 45^{\prime} \mathrm{W} \\
69^{\circ} 35^{\prime} \mathrm{W}\end{array}$ \\
\hline \multicolumn{6}{|c|}{ Boutelle Seamount } \\
\hline 0 & $\begin{array}{r}0.74 \\
.76 \\
.89 \\
1.24\end{array}$ & $\begin{array}{l}126^{\circ} 15^{\prime} \mathrm{W} \\
129^{\circ} 30^{\prime} \mathrm{W} \\
135^{\circ} 15^{\prime} \mathrm{W} \\
140^{\circ} 45^{\prime} \mathrm{W}\end{array}$ & $\begin{array}{l}-24^{\circ} 30^{\prime} \\
-13^{\circ} 30^{\prime} \\
+8^{\circ} 200^{\prime} \\
+27^{\circ} 5^{\prime}\end{array}$ & $\begin{array}{l}-18^{\circ} \\
-24^{\circ} 35^{\prime} \\
-36^{\circ} 5^{\prime} \\
-47^{\circ} 40^{\prime}\end{array}$ & $\begin{array}{l}173^{\circ} 15^{\prime} \mathbf{E} \\
171^{\circ} 35^{\prime} \mathbf{E} \\
116^{\circ} 55^{\circ} \mathbf{E} \\
163^{\circ} 25^{\prime} \mathbf{E}\end{array}$ \\
\hline \multicolumn{6}{|c|}{ Hoke Seamount } \\
\hline $\begin{array}{l}0 \\
0 \\
3 \\
\\
7.53 \\
10\end{array}$ & $\begin{array}{l}3.91 \\
2.70 \\
2.04 \\
1.66 \\
2.02\end{array}$ & $\begin{array}{l}17^{\circ} 10^{\prime} \mathbf{E} \\
17^{\circ} 35^{\prime}, \mathbf{E} \\
18^{\circ} 5^{\prime} \mathbf{E} \\
19^{\circ} 15^{\circ} \mathbf{E} \\
20^{\circ} 5^{\prime} \mathbf{E}\end{array}$ & $\begin{array}{l}+30^{\circ} 55^{\prime} \\
+18^{\circ} 5^{\prime} \\
+1^{\circ} 40^{\prime} \\
-33^{\circ} 55^{\prime} \\
-49^{\circ} 10^{\prime}\end{array}$ & $\begin{array}{l}+68^{\circ} 5^{\prime} \\
+61^{\circ} 55^{\prime} \\
+54^{\circ} 20^{\prime} \\
+36^{\circ} \\
+24^{\circ} 55^{\prime}\end{array}$ & $\begin{array}{r}3^{\circ} 50^{\prime} \mathbf{E} . \\
13^{\circ} 40^{\prime} \mathbf{E} . \\
20^{\circ} 50^{\prime} \mathbf{E} \\
30^{\circ} 5^{\prime} \mathbf{E} \\
3^{\circ} 55^{\prime} \mathbf{E} .\end{array}$ \\
\hline
\end{tabular}

Next, for each seamount the vector $J_{n}$ and the locus of the north virtual pole was calculated as a function of $K$. A suitable set of values of $K$ was chosen, which includes the value $K_{1}$ that minimizes $J_{n}$. The results of these calculations are shown in table 3 and the loci of the virtual poles in figures 10 and 11 .

\section{DISCUSSION OF RESULTS}

Because of a seamount's volcanic nature, the remanent magnetization of a seamount is probably thermoremanent. The effect upon the magnetization of nearsurface alteration is of little significance for the bulk of a seamount's mass. Hence, it can be assumed that the remanent magnetization is parallel to the geomagnetic field which prevailed at the time of the cooling below the Curie point.

The values found for the total intensity of magnetization $J$-namely, $0.74,1.89$, and 3.91 , in $10^{-3}$ emu (electromagnetic units) in Boutelle, Maher and Hoke Seamounts, respectively - appear reasonable for oceanic basalts. These electromagnetic units, and as used later in this paper, are in the cgs system. By studying the magnetic anomalies, Van Voorhis and Walczak (1963) found a value of $10 \times 10^{-3} \mathrm{emu}$ for Kelvin Seamount in the northwest Atlantic. Vine and Matthews (1963), by studying the magnetic anomalies of volcano-like features in the Indian Ocean, have established a value for $J$ of $5 \times 10^{-3} \mathrm{emu}$, and $K_{\mathrm{app}}$ $=13.3 \times 10^{-3} \mathrm{emu}$.

The lower limits calculated for the remanent magnetization $J_{n}$ (table 2) are $0.74,1.36$, and 1.66 , in $10^{-3}$ emu in Boutelle, Maher, and Hoke Seamounts, respectively. They are consistent with other observations. On dredged material from a seamount north of Madeira Laughton, Hill, and Allan (1960) measured a value for $J_{n}$ of $5 \times 10^{-3} \mathrm{emu}$. Matthews (1961), on lava samples from a small abyssal hill on the North Atlantic, measured a median value for $J_{n}$ of $5 \times 10^{-3} \mathrm{emu}$. Bullard and Mason (1963), for basalt dredged from the Mendocino fault, indicated that $J_{n}$ may reach the exceptionally large value of $0.3 \mathrm{emu}$.

In Maher, Boutelle, and Hoke Seamounts there is a great discrepancy between the directions calculated for the total magnetization (table 2) and the directions of the present geomagnetic field. To investigate the position of the north virtual pole, its locus as a function of $K$ has been calculated for the three seamounts in the manner described in this paper. The loci for Maher and Hoke Seamounts are shown in figure 10, and the locus for Boutelle Seamount in figure 11, all on meridional stereographic projections. The loci are wide apart and do not intersect for the assumed range of values of $K$. The directions of their $J_{n}$ are wide apart. No reasonable values of $K$ can be found which will yield directions of $J_{n}$ convergent on a single pole for these three seamounts. Therefore, two alternative explanations are to be considered: (a) the seamounts, when they acquired their TRM, were at different positions with respect to the geomagnetic pole than they are at present, and also they are of different ages, or (b) they are of the same age, but relative changes and local rotations have occurred.

Several investigators have proposed reconstructions of the track of the geomagnetic pole for different continents through geologic time, based on paleomagnetic data. The tracks for Australia and North 
America (Runcorn, 1962) and for South America (Creer, 1964), are shown in figures 10 and 11. No track has been presented as yet for the Pacific area. Granted that there are discrepancies between different reconstructions of these tracks, certain features of the phenomenon are well established. The geomagnetic pole increasingly departs from its present position when receding in time from the Cenozoic. The data for each continent are more internally consistent than the data from continent to continent, and there are large differences between the tracks for the different continents. As the three seamounts analyzed in this paper adjoin the North American continent, it is important to compare the loci for the virtual pole calculated for them with the track for that continent.

To account for the deviations between the seamounts'

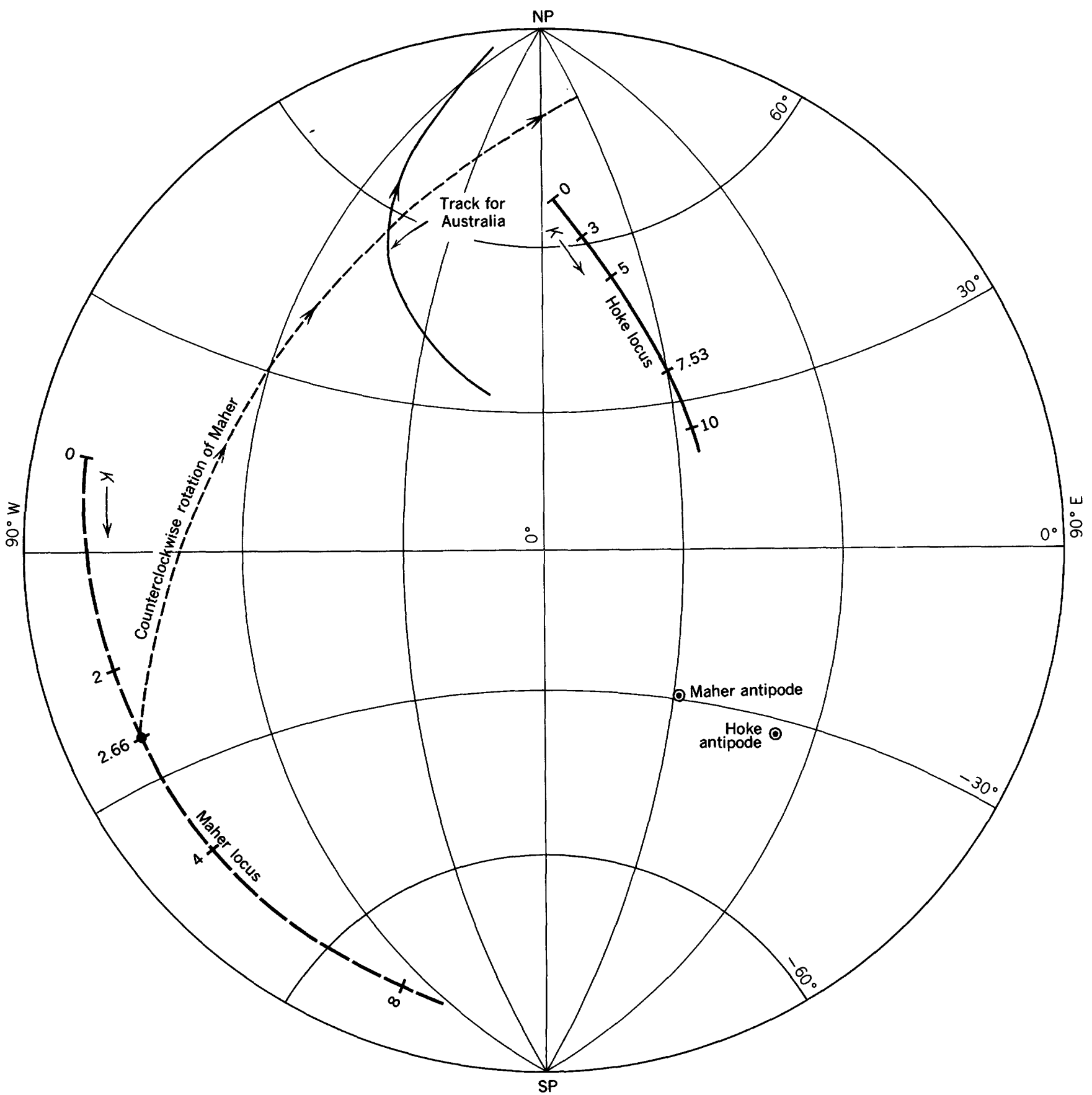

Figure 10. - Loci of north virtual pole for Maher and Hoke Seamounts. Values of $K$ along loci are in $10^{-3}$ emu units. The tracks of the paleomagnetic pole for Australia and North America are taken from Runcorn (1962), and the one for South America from Creer (1964). A meridional stereographic projection of the hemisphere $90^{\circ} \mathrm{W} .-0^{\circ}-90^{\circ} \mathrm{E}$. is used. 
loci and the track for North America, we can consider different kinds of simple relative motions. Hoke's locus falls about $90^{\circ}$ of arc west of the track for that continent, yet only about $20^{\circ}$ of arc east of that for Australia. A northward shift of the locus by about $20^{\circ}$ of arc would bring it into practical coincidence with the track for North America. In particular, the point corresponding to $K=0$ would coincide with the present pole. On the other hand, an eastward shift of $90^{\circ}-105^{\circ}$ of arc would bring the locus into coincidence with the Jurassic-Silurian segment of the track. Yet, since Hoke and Boutelle Seamounts are only about $7^{\circ}$ of arc away from the western edge of North America, their feasible westward relative motion is not more than that amount. Otherwise, they would have had to slip under the continent.

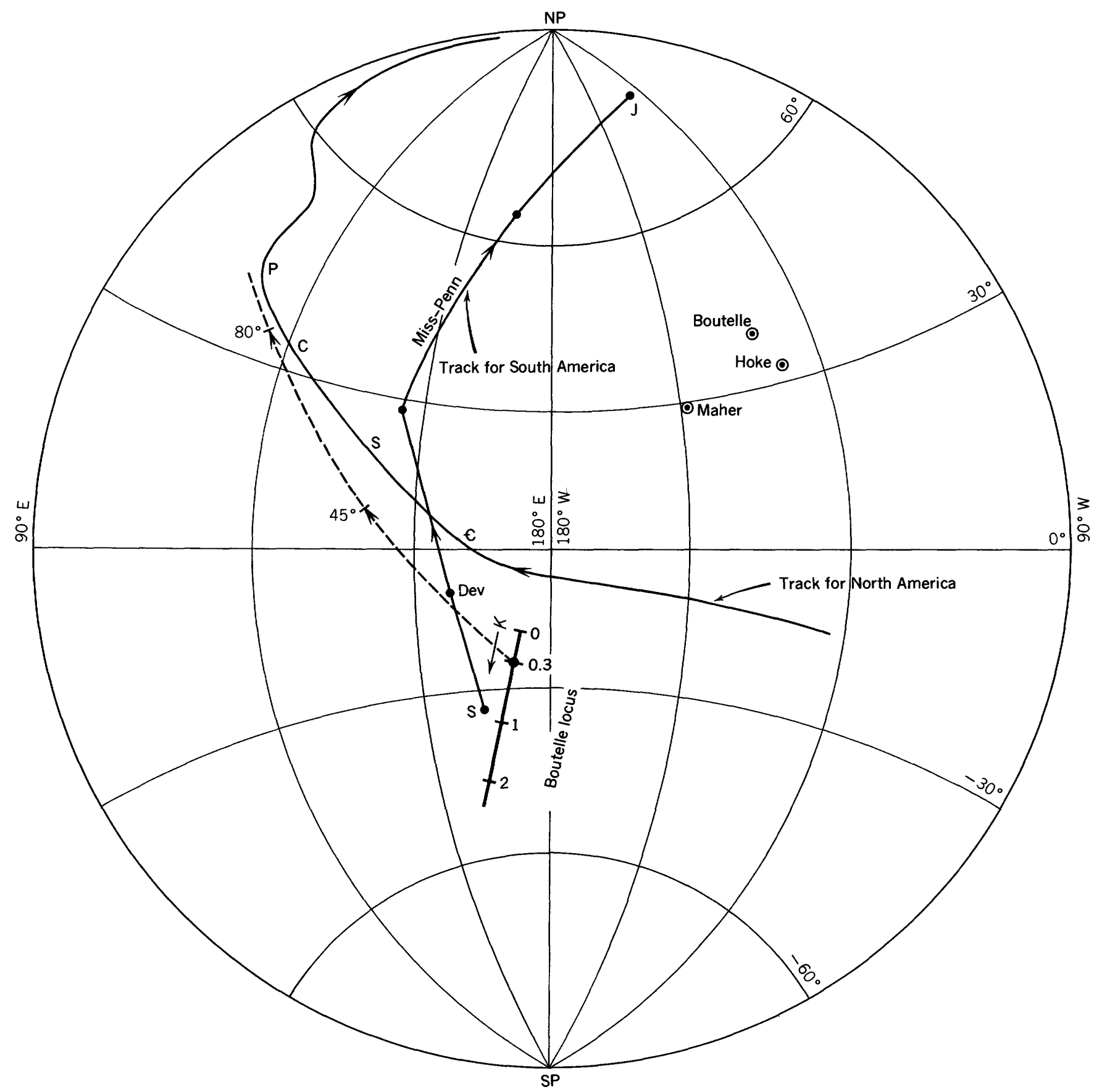

Figure 11.-Locus of north virtual pole for Boutelle Seamount. Values of $K$ along locus are in $10^{-3}$ emu units. The track of the paleomagnetic pole for North America is taken from Runcorn (1962) and the one for South America from Creer (1964). A meridional stereographic projection of the hemisphere $90^{\circ} \mathrm{W} .-180^{\circ} \mathrm{W} .-270^{\circ} \mathrm{W}$. is used. 
Boutelle's locus falls south of the track for North America, but with its closest point only about $15^{\circ}$ of arc away. With a northward shift of $15^{\circ}-50^{\circ}$ of arc, for the range of $K$ values shown in figure 11, the locus would intersect the track at approximately the Cambrian segment. On the other hand, an eastward shift of the locus, which would not change the situation appreciably, is deemed unfeasible as explained before.

Because of the proximity of Boutelle and Maher Seamounts and of the generally east-west orientation of the intervening fracture zones, any meridional shift should be of generally the same magnitude for both of these seamounts. As explained before, no meridional shift can bring their loci to overlap the track for North America.

If it were assumed that the earth's magnetic field was reversely polarized at the time when Hoke and Maher became magnetized, then the antipode of the locus should be considered instead of the locus itself. Thereby, the Hoke and Maher antipodal loci are found to fall near the track for North America. For example, for Hoke Seamount the point corresponding to $K=10 \times 10^{-3}$ emu, and for Maher Seamount that point corresponding to $K=0$ falls about $20^{\circ}$ of arc away from the track.

The hypothesis proposed by Vine and Matthews (1963) about the origin of the main Pacific crustal layers bears on these interpretations. First, if the oceanic crust had spread eastward away from the midPacific, the seamounts could have been carried eastward by up to approximately $90^{\circ}$. Second, if instead the oceanic crust had spread westward from the East Pacific Rise, the positions in the upper mantle corresponding to the seamounts could have been carried westward by up to approximately $20^{\circ}$. In the first alternative the loci for the seamounts would be found eastward of the track for North America, which is opposite of where it occurs. If the second alternative were true, the seamounts could have shifted westward only a maximum of about $7^{\circ}$ of arc. Hence, a simple interpretation of these seamounts' data gives no support to the spreading-floor hypothesis.

In the northeast Pacific, because of horizontal displacements along the fracture zones, it is conceivable that certain adjoining crustal blocks may have been rotated about vertical axes. Thus, the magnetization vector would be rotated by an amount equal to the rotation undergone by the supporting block after the seamount was built upon it. On the other hand, the angle of inclination would not be affected by such rotation. As the average velocity of slip along a fracture zone may be of the order of a few centimeters per hundred years, such displacements of up to hundreds of kilometers which have been inferred would require tens of millions of years. As the growth and cooling of a seamount can be accomplished in much less than $1 \mathrm{~m} . y$. , the rotation during such a period could amount at most to a few degrees. Indeed the magnetic maps of the area of the three seamounts (Mason and Raff, 1961; Raff and Mason, 1961) suggest that block rotations might have occurred. The maguetic pattern is partitioned in blocks, each block being characterized by a certain linear trend which changes direction from block to block. In between there are zones with a disorderly pattern. Some of these changes of direction are appreciable. For example, the linear pattern turns by about $20^{\circ}$ at about lat $44^{\circ} \mathrm{N}$. and long $130^{\circ} \mathrm{W}$. (Raff and Mason, 1961, pl. 1).

Maher Seamount is about 10 nautical miles to the south of the Murray fracture zone (fig. 9), where the right-lateral displacement of $154 \mathrm{~km}$ has been proposed (Menard and Vacquier, 1958; Mason, 1958). The shearing action implied by such displacement, upon the crust on the south side of the fracture, could produce a clockwise rotation. Boutelle Seamount is between the Mendocino and Pioneer fracture zones. The proposed left-lateral displacements of $1,160 \mathrm{~km}$ along the Mendocino and of $265 \mathrm{~km}$ along the Pioneer fracture zones (Vacquier and others, 1961) indicate a shearing action which could produce counterclockwise rotation in the area of Boutelle Seamount. Thus, the east to southeast declination of $\boldsymbol{J}_{n}$ in Maher Seamount and the southwest declination in Boutelle Seamount as shown in table 3 could be attributed, in part, to such block rotations. To compensate for them, the loci of Maher and Boutelle Seamounts may be rotated anticlockwise and clockwise, respectively, about the corresponding seamounts. The arcs thus described by a point of the loci of Maher and Boutelle Seamounts are shown in figures 10 and 11 , respectively. It is observed that with this correction the loci approach the tracks of the geomagnetic pole shown in these figures.

\section{PROPOSED PROCEDURE TO INTERPRET THE DATA OF MANY SEAMOUNTS}

I shall now describe the procedure to be used if the data of many seamounts were available. The uncertainties in the interpretation for the three seamounts arise mainly because three is too few.

The simplest situation is that of a group of seamounts formed at the same geologic time and when there have been no relative rotations or displacements of one seamount with respect to the others. Then the loci for the virtual pole for the different seamounts should intersect at one point. The value of the susceptibility $\dot{K}$ for each seamount could be read off, along each locus, at the point of intersection.

Next we may consider a group of equal-age seamounts when relative rotations may have occurred. The 
calculated loci of the virtual pole can be rotated about their seamounts. Each point of a locus, corresponding to a particular value of $K$, would describe an arc of circle about the seamount. The area common to all these arcs for the likely range of values of $K$ defines an enclosure within which the virtual pole would be found. The enclosure thus defined will be called a corral. The closeness in the determination of the value of $K$ for the different seamounts with this procedure would hinge upon the size and shape of the corral, which in turn would depend on the particular configuration of the seamounts.

Furthermore, to investigate possible displacements, the seamounts should first be classified in groups of seamounts which are expected to have equal displacements, and the analysis of each group would proceed as indicated before. For example, seamounts between two fracture zones could be assumed to have undergone equal displacements. For each group a corral would be defined for the virtual pole. Then it should be possible to bring these corrals into coincidence by linear displacements, from which the motions along the fracture zones could be deduced.

For a group of different-age seamounts, with no displacements or rotations between them, the approach would be as follows: The locus for each seamount would be established as a function of $K$. These loci should intersect the track of the virtual pole as a function of geologic time. If this track is unknown, a smooth line should be sought intersecting all the loci, as a first approximation to the track of the virtual pole. This procedure might give a good definition of the track of the pole if data for many seamounts of widely different ages were available.

The most difficult case is when dealing with seamounts of different ages, and when rotations and displacements between them have to be considered. In such a case, groups of seamounts, which should have equal displacements, would be analyzed separately; and next, the group results would be analyzed as outlined in the previous paragraphs.

\section{CONCLUSIONS}

The triple-field method of analysis of a magnetic anomaly gives, without trial and error, the total internal magnetization of a given geologic body as to direction, sense, and magnitude under the assumption of uniform internal magnetization throughout the body or throughout each of a number of given regions in which the body may be subdivided. Besides, the examination of the three hypothetical fields permits a semiquantitative analysis of the problem. By taking advantage of the inherently high precision of digital computers, we can readily calculate the hypo- thetical fields for a model of the body by a numerica] differentiation of the gravimetric field.

The concept of biased-field anomaly, as an aigorithm built in the computer program, gives the option of obtaining several quantities geophysically significant, namely (a) an arbitrary component of the anomaly field intensity, (b) the total-intensity anomaly as conventionally defined in aeromagnetic prospecting, and (c) the magnitude of the anomaly field intensity.

Seamounts offer a promising field of application for the triple-field method, because of their commonly distinctive anomalies and known shapes. It may not be enough to consider only the mass standing over the ocean floor, but also a root may have to be included to take into account the demagnetization by reheating and the subsequent remagnetization during cooling of the rocks underlying the volcanic mass. The magnetic field observed in certain seamounts can be reproduced very well under the simple assumption that their masses above the ocean floor are uniformly magnetized in a direction which may be different from that of the present geomagnetic field.

By examining the vector relationship between $J, J_{n}$, and $\overrightarrow{K \Omega}$ as a function of $K$, we find the TRM vector $J_{n}$ can be a function of $K$, and from the direction of $J_{n}$ a locus for the north virtual pole can be established. Such loci, when the data for many seamounts are available, would permit the investigation of the positions of the virtual pole and of possible differential crustal displacements and rotations.

The directions of the TRM in Maher, Boutelle, and Hoke Seamounts appear to be substantially different from those of the present field. Yet, under certain assumptions the loci for the virtual pole can be reconciled with the track for the paleomagnetic pole which has been proposed for the North American continent. Hoke and Maher Seamounts would have become magnetized at a time when the field was reversed. Boutelle and Hoke Seamounts would be of Cambrian age or older, and Maher Seamount possibly much younger. Since the Boutelle locus and the Hoke antipodal locus apparently lie within the limits of confidence of the track for North America, only none or a small southward relative motion of these seamounts would have taken place. Alternatively, rotation of Boutelle and Maher Seamounts, to compensate for a possible rotation arising from the shearing along the nearby fracture zones, would bring the loci nearer to the tracks proposed for North America and South America. A systematic analysis, in the manner explained, of the magnetization of a greater number of seamounts in the northeast Pacific may be useful. 


\section{REFERENCES}

Bhattacharyya, B. K., 1964, Magnetic anomalies due to prismshaped bodies with arbitrary polarization: Geophysics, v. 29 , no. 4 , p. 517-531.

Bott, M. H. P., 1963, Two methods applicable to computers for evaluating magnetic anomalies due to finite threedimensional bodies: Geophys. Prosp., v. 11, no. 3, p. 292-299.

Bullard, E. C., and Mason, R. G., 1963, The magnetic field over the oceans, in Hill, M. N., ed., The sea-ideas and observations on progress in the study of the seas: New York, Interscience Publishers, v. 3, The earth beneath the sea, p. 175-217.

Carsola, A. H., and Dietz, R. S., 1952, Submarine geology of two flat-topped northeast Pacific seamounts: Am. Jour. Sci., v. 250, no. 7, p. 481-497.

Chapman, Sydney, and Bartels, Julius, 1940, Geomagnetism, v. 1: Oxford, Clarendon Press, 542 p.

Creer, K. M., 1964, A reconstruction of the continents for the upper Paleozoic from paleomagnetic data: Nature, v. 203, no. 4950 , p. $1115-1120$.

Grant, F. S., 1952, Three-dimensional interpretation of gravitational anomalies: Geophysics, v. 8, no. 2, p. 344-364.

Hamilton, E. L., 1956, Sunken islands in the mid-Pacific mountains: Geol. Soc. America Mem. 64, 95 p.

Heezen, B. C., 1962, The deep sea floor, in Runcorn, S. K., ed., Continental drift: New York, Academic Press, p. 235-288.

Heezen, B. C., and Menard, H. W., 1963, Topography of the deep-sea floor, in Hill, M. N., ed., The sea-ideas and observations on progress in the study of the seas: New York, Interscience Publishers, v. 3, The earth beneath the sea, p. 233-280.

Henderson, R. G., and Allingham, J. W., 1964, The magnetization of an inhomogeneous laccolith calculated on a digital computer, pt. 2 of Computers in the mineral industries: Stanford Univ. Pubs. Geol. Sci., v. 9, no. 2, p. 481-497.

Hess, H. H., 1946, Drowned ancient islands of the Pacific Basin: Am. Jour. Sci., v. 244, no. 11, p. 772-791.

Ingersoll, L. R., Zobel, O. J., and Ingersoll, A. C., 1954, Heat conduction with engineering, geological and other applications: Madison, Univ. Wisconsin Press, $325 \mathrm{p}$.

Kellogg, O. D., 1929, Foundations of potential theory: New York, Frederick Ungar Publishing Co., 384 p.

Laughton, A. S., Hill, M. N., and Allan, T. D., 1960, Geophysical investigations of a seamount 150 miles north of Madeira: Deep-Sea Research, v. 7, no. 2, p. 117-141.

MacDonald, G. A., 1963, Physical properties of erupting Hawaiian magmas: Geol. Soc. America Bull., v. 74, no. 8, p. 1071-1077.

MacDonald, G. A., and Finch, R. H., 1950, The June 1950 eruption of Mauna Loa: Volcano Letter, no. 509, p. 1-6.

Mason, R. G., 1958, A magnetic survey off the west coast of the United States: Geophys. Jour. [London], v. 1, no. 4, p. 320-329.

Mason, R. G., and Raff, A. D., 1961, Magnetic survey off the west coast of North America, $32^{\circ} \mathrm{N}$ latitude to $42^{\circ} \mathrm{N}$ latitude: Geol. Soc. America Bull., v. 72, no. 8, p. 1259-1266.

Matthews, D. H., 1961, Lavas from an abyssal hill on the floor of the North Atlantic Ocean: Nature, v. 190, no. 4771, p. 158-159.

Maxwell, J. C., 1904, A treatise on electricity and magnetism, v. 2: Oxford, Clarendon Press, 500 p.
Menard, H. W., 1955, Deformation of the northeastern Pacific basin and the west coast of North America: Geol. Soc. America Bull., v. 66, no. 9, p. 1149-1198.

1959, Geology of the Pacific sea floor: Experientia, v. 15, no. 6, p. 205-214.

1960, The East Pacific Rise: Science, v. 132, no. 3441, p. 1737-1746.

1964, Marine geology of the Pacific: New York, McGrawHill Book Co., 271 p.

Menard, H. W., and Ladd, H. S., 1963, Oceanic islands, seamounts, guyots, and atolls, in Hill, M. N., ed., The seaideas and observations on progress in the study of the seas: New York, Interscience Publishers, v. 3, The earth beneath the sea, p. 365-385.

Menard, H. W., and Vacquier, Victor, 1958, Magnetic survey of part of the deep sea floor off the coast of California: U.S. Office Naval Research, Research Rev., June, p. 1-5.

Morgan, N. A., and Grant, F. S., 1963, High speed calculation of gravity and magnetic profiles across two-dimensional bodies having an arbitrary cross section: Geophys. Prosp., v. 11, no. 1 , p. 10-15.

Nagata, Takesi, 1953, Rock-magnetism: Tokyo, Maruzen Co., $232 \mathrm{p}$.

Nayudu, Y. R., 1962, A new hypothesis for origin of guyots and seamount terraces, in MacDonald, G. A., and Kuno, Hisashi, Crust of the Pacific Basin: Am. Geophys. Union Geophys. Mon. 6, p. 171-180.

Peter, George, and Stewart, H. B., 1965, Ocean surveys: The systematic approach: Nature, v. 206, no. 4988, p. 1017-1018.

Press, Frank, and Ewing, Maurice, 1952, Magnetic anomalies over oceanic structures: Am. Geophys. Union Trans., v. 33, no. 3 , p. 349-355.

Raff, A. D., 1962, Further magnetic measurements along the Murray fault: Jour. Geophys. Research, v. 67, no. 1, p. 417-418.

Raff, A. D., and Mason, R. G., 1961, Magnetic survey off the west coast of North America, $40^{\circ} \mathrm{N}$ latitude to $52^{\circ} \mathrm{N}$ latitude: Geol. Soc. America Bull., v. 72, no. 8, p. 1267-1270.

Rittmann, Alfred, 1962, Volcanoes and their activity: New York, John Wiley \& Sons, 305 p.

Runcorn, S. K., 1962, Paleomagnetic evidence for continental drift and its geophysical cause, in Runcorn, S. K., ed., Continental drift: New York, Academic Press, p. 1-39.

Talwani, Manik, and Heirtzler, J. R., 1964, Computation of magnetic anomalies caused by two-dimensional structures of arbitrary shape, pt. 1 of Computers in the mineral industries: Stanford Univ. Pubs. Geol. Sci., v. 9, no. 1, p. 464-479.

Talwani, Manik, Le Pichon, Xavier, and Heirtzler, J. R., 1965, East Pacific Rise-The magnetic pattern and the fracture zones: Science, v. 150, no. 3700, p. 1109-1115.

U.S. Naval Oceanographic Office, 1962, A marine magnetic survey south of the Hawaiian Islands: U.S. Naval Oceanog. Office, Tech. Rept. TR-137, 47 p.

Vacquier, Victor, 1962a, Magnetic evidence for horizontal displacements in the floor of the Pacific Ocean, in Runcorn, S. K., ed., Continental drift: New York, Academic Press, p. 135-144.

-1962b, A machine method for computing the magnitude and the direction of magnetization of a uniformly magnetized body from its shape and a magnetic survey, in Nagata, Takesi, Benedum earth magnetism symposium: Pittsburgh, Univ. Pittsburgh Press, p. 123-137. 
Vacquier, Victor, Raff, A. D., and Warren, R. E., 1961, Horizontal displacements in the floor of the northeastern Pacific Ocean: Geol. Soc. America Bull., v. 72, no. 8, p. 1251-1258.

Vacquier, Victor, Steenland, N. C., Henderson, R. G., and Zietz, Isidore, 1951, Interpretation of aeromagnetic maps: Geol. Soc. America Mem. 47, 151 p.

Van Voorhis, Gerald, and Walczak, James, 1963, Summary of magnetization computations for Kelvin Seamount: U.S. Naval Oceanog. Office, Informal Manuscript Rept. M-8-63, $19 \mathrm{p}$.

Vine, F. J., and Matthews, D. H., 1963, Magnetic anomalies over oceanic ridges: Nature, v. 199 , no. 4897 , p. 947-949.
Vine, F. J., and Wilson, J. T., 1965, Magnetic anomalies over a young oceanic ridge off Vancouver Island: Science, v. 150 , no. 3695 , p. $485-489$.

Wentworth, C. K., Carson, M. H., and Finch, R. H., 1945, Discussion on the viscosity of lava: Jour. Geology, v. 53, no. 2, p. 94-104.

Wilson, J. T., 1965a, A new class of faults and their bearing on continental drift: Nature, v. 207, no. 4995, p. 343-347. - 1965b, Submarine fracture zones, aseismic ridges, and the International Council of Scientific Unions LineProposed western margin of the East Pacific Ridge: Nature, v. 207, no. 5000, p. 907-911.

1965c, Transform faults, oceanic ridges, and magnetic anomalies southwest of Vancouver Island: Science, v. 150, no. 3695 , p. $482-485$. 